\title{
Differential Mechanisms of CRF1 and CRF2 Receptor Functions in the Amygdala in Pain-Related Synaptic Facilitation and Behavior
}

\author{
Yu Fu and Volker Neugebauer \\ Department of Neuroscience and Cell Biology, The University of Texas Medical Branch, Galveston, Texas 77555-1069
}

\begin{abstract}
A major site of extrahypothalamic expression of corticotropin-releasing factor (CRF) and its G-protein-coupled CRF1 and CRF2 receptors is the amygdala, a key player in emotions and affective disorders. Pain-related plasticity in the laterocapsular division of the central nucleus of the amygdala (CeLC) generates emotional-affective responses and anxiety-like behavior. CRF1 receptor antagonists have anxiolytic effects. Although both CRF1 and CRF2 receptors couple positively to adenylyl cyclase, they can have opposite effects, but the underlying mechanism is unknown. This study addressed CRF1 and CRF2 receptor functions and mechanisms in the amygdala in a model of arthritic pain. Using whole-cell patch-clamp recordings of CeLC neurons, we found that a selective CRF1 receptor antagonist (NBI27914 [5-chloro-4-( $N$-(cyclopropyl)methyl- $N$-propylamino)-2-methyl-6-(2,4,6-trichlorophenyl)]) amino-pyridine inhibited synaptic facilitation in brain slices from arthritic rats through a postsynaptic mechanism. Inhibition of the NMDA receptor-mediated synaptic component was occluded by a protein kinase $\mathrm{A}$ (PKA) inhibitor, consistent with our previous demonstration of PKA-dependent increased NMDA receptor function in arthritis pain-related plasticity. NBI27914 also decreased neuronal excitability through inhibition of highly tetraethylammonium (TEA)-sensitive ion channels that contribute to action potential repolarization and firing rate. In contrast, a CRF2 receptor antagonist (astressin-2B [cyclo(31-34) [D-Phe11,His12,C $\alpha$ MeLeu13,39, Nle17, Glu31, Lys34] Ac-Sauvagine(8 - 40)]) facilitated synaptic transmission through presynaptic inhibition of GABAergic transmission (disinhibition). NBI27914 inhibited arthritis painrelated behaviors (audible and ultrasonic vocalizations and hindlimb withdrawal reflexes). Astressin-2B had no significant behavioral effect. The data suggest that endogenous CRF1 receptor activation in the amygdala contributes to pain-related synaptic facilitation, increased excitability, and pain behavior through a postsynaptic mechanism involving activation of PKA and highly TEA-sensitive $\mathrm{K}^{+}$-currents. Presynaptic CRF2 receptor-mediated inhibition does not reach behavioral significance.
\end{abstract}

Key words: amygdala; synaptic plasticity; pain; CRF; PKA; vocalization; arthritis

\section{Introduction}

The present study focused on the role of corticotropin-releasing factor 1 (CRF1) and CRF2 receptors in the amygdala in painrelated facilitation and behavior. The amygdala is a major site of extrahypothalamic CRF expression and a key element of the circuitry through which CRF contributes to anxiety and affective disorders (Gray, 1993; Reul and Holsboer, 2002; Bale and Vale, 2004; Asan et al., 2005). CRF1 receptors have emerged as drug targets for depression and anxiety disorders (Chalmers et al., 1996; Takahashi, 2001; Dautzenberg and Hauger, 2002; Reul and Holsboer, 2002; Charney, 2003; Bale and Vale, 2004). CRF1 receptor antagonists have been used successfully in humans for depression and anxiety (Zobel et al., 2000; Kunzel et al., 2005).

\footnotetext{
Received Sept. 25, 2007; revised Feb. 22, 2008; accepted Feb. 22, 2008.

This work was supported by National Institutes of Health Grants NS-38261 and NS-11255. We thank Dr. Marco Martina (Northwestern University, Chicago, IL) for his valuable advice regarding Kv3 channel function.

Correspondence should be addressed to Dr. Volker Neugebauer, Department of Neuroscience and Cell Biology, The University of Texas Medical Branch, 301 University Boulevard, Galveston, TX 77555-1069. E-mail: voneugeb@utmb.edu.

DOI:10.1523/JNEUROSCI.0227-08.2008

Copyright $\odot 2008$ Society for Neuroscience $\quad 0270-6474 / 08 / 283861-16 \$ 15.00 / 0$
}

Pain carries a negative affective valence and is closely related to anxiety and depression (Rome and Rome, 2000; Grachev et al., 2001; Rhudy and Meagher, 2003; Turk, 2003; Gallagher and Verma, 2004). The amygdala is now recognized as an important player in the emotional-affective dimension of pain (Heinricher and McGaraughty, 1999; Rhudy and Meagher, 2001; Gauriau and Bernard, 2002; Neugebauer et al., 2004; Neugebauer, 2006; Ji et al., 2007; Pedersen et al., 2007). Our previous studies demonstrated central sensitization (Neugebauer and Li, 2003; Li and Neugebauer, 2004a,b, 2006; Han et al., 2005b; Ji and Neugebauer et al., 2007) and synaptic plasticity (Neugebauer et al., 2003; Han et al., 2004, 2005b, 2006; Bird et al., 2005) in the laterocapsular division of the central nucleus of the amygdala (CeLC) in the kaolin/carrageenan-induced arthritis pain model. Pain-related synaptic plasticity in the CeLC was confirmed in a model of chronic neuropathic pain (Ikeda et al., 2007) and was mimicked by tetanic stimulation of presumed nociceptive inputs from the parabrachial area (PB) (Lopez de Armentia and Sah, 2007). Pharmacologic inhibition of the central nucleus decreased nocifensive and affective pain responses in arthritic (Han and Neugebauer, 2005; Han et al., 2005b), visceral (Tanimoto et al., 2003), and neuropathic pain (Pedersen et al., 2007) models and in the pro- 
longed phase of the Formalin test (Carrasquillo and Gereau, 2007).

Arthritis pain-related plasticity in the CeLC requires protein kinase A (PKA)-dependent increased NMDA receptor function (Bird et al., 2005). CRF binds to G-protein-coupled CRF1 and CRF2 receptors, both of which typically activate the cAMP-PKA signal transduction pathway (Dautzenberg and Hauger, 2002; Reul and Holsboer, 2002; Blank et al., 2003; Arzt and Holsboer, 2006). Despite similar effector mechanisms and a $70 \%$ sequence homology, these receptors can mediate different, sometimes opposing functions (Reul and Holsboer, 2002; Charney, 2003; Bale and Vale, 2004). Selective antagonists have become available, including NBI27914 [5-chloro-4-( $N$-(cyclopropyl)methyl- $N$ propylamino)-2-methyl-6-(2,4,6-trichlorophenyl) aminopyridine] (Hoare et al., 2003) and astressin-2B [Cyclo(31-34) [D-Phe11,His12,C $\alpha$ MeLeu13,39, Nle17, Glu31, Lys34] Ac-Sauvagine(8-40)] (CRF2) (Rivier et al., 2002), which were used in the present study.

Previous biochemical (Sinniger et al., 2004; Greenwood-Van Meerveld et al., 2006; Ulrich-Lai et al., 2006) and behavioral (Lariviere and Melzack, 2000; McNally and Akil, 2002) studies point to the amygdala as an important site of CRF-mediated pain modulation, but the role of endogenously activated CRF1 and CRF2 receptors in the amygdala is not known. The present study used a multidisciplinary approach at the system and cellular levels to determine the effects of selective CRF1 and CRF2 receptor antagonists on pain-related synaptic facilitation in the amygdala, the underlying mechanisms and behavioral consequences.

\section{Materials and Methods}

Arthritis pain model

A mono-arthritis was induced in the left knee joint of adult rats as described in detail previously (Neugebauer and Li, 2003; Neugebauer et al., 2003). A kaolin suspension $(4 \%, 80-100 \mu \mathrm{l})$ was injected into the joint cavity through the patellar ligament with a syringe ( $1 \mathrm{ml}, 25 \mathrm{G} 5 / 8)$. After repetitive flexions and extensions of the knee for $15 \mathrm{~min}$, a carrageenan solution $(2 \%, 80-100 \mu \mathrm{l})$ was injected into the knee joint cavity, and the leg was flexed and extended for another $5 \mathrm{~min}$. This treatment paradigm reliably leads to inflammation and swelling of the knee within $1-3 \mathrm{~h}$, reaches a maximum plateau at 5-6 h, and persists for days (Neugebauer et al., 2007). Electrophysiological and behavior measurements of arthritis pain-related changes were made at the $6 \mathrm{~h}$ time point (plateau phase).

\section{Electrophysiology: patch-clamp recording}

Amygdala slice preparation. Brain slices containing the central nucleus of the amygdala $(\mathrm{CeA})$ were obtained from arthritic rats and normal rats (150-250 g; Sprague Dawley). Rats were decapitated, and the brains were quickly dissected out and blocked in cold $\left(4^{\circ} \mathrm{C}\right)$ artificial CSF (ACSF). ACSF contained the following (in $\mathrm{mm}$ ): $117 \mathrm{NaCl}, 4.7 \mathrm{KCl}, 1.2 \mathrm{NaH}_{2} \mathrm{PO}_{4}$, $2.5 \mathrm{CaCl}_{2}, 1.2 \mathrm{MgCl}_{2}, 25 \mathrm{NaHCO}_{3}$, and 11 glucose. ACSF was oxygenated and equilibrated to $\mathrm{pH} 7.4$ with a mixture of $95 \% \mathrm{O}_{2} / 5 \% \mathrm{CO}_{2}$. Coronal brain slices $(500 \mu \mathrm{m})$ were prepared using a Vibroslice (Camden Instruments, London, UK). After incubation in ACSF at room temperature $\left(21^{\circ} \mathrm{C}\right)$ for at least $1 \mathrm{~h}$, a single brain slice was transferred to the recording chamber and submerged in $\operatorname{ACSF}\left(31 \pm 1^{\circ} \mathrm{C}\right)$, which superfused the slice at $\sim 2 \mathrm{ml} / \mathrm{min}$. Only one or two brain slices per animal were used, one neuron was recorded in each slice, and a fresh slice was used for each new experimental protocol. Numbers in the manuscript refer to the number of neurons tested for each parameter.

Whole-cell patch-clamp recording. Whole-cell recordings using the "blind" patch technique were obtained from neurons in the CeLC (see Fig. 1) as described previously (Neugebauer et al., 2003; Han et al., 2004, 2005b, 2006; Bird et al., 2005). The different nuclei of the amygdala and the CeA subdivisions are easily discerned under the microscope (see Fig. 1). Patch electrodes (4-6 M $\Omega$ tip resistance) were made from borosilicate glass capillaries (1.5 and $1.12 \mathrm{~mm}$, outer and inner diameter, respectively; Drummond Scientific, Broomall, PA), using a Flaming-Brown micropipette puller (P-80/PC; Sutter Instruments, Novato, CA). The internal solution of the recording electrodes contained the following (in mM): $122 \mathrm{~K}$-gluconate, $5 \mathrm{NaCl}, 0.3 \mathrm{CaCl}_{2}, 2 \mathrm{MgCl}_{2}, 1$ EGTA, 10 HEPES, $5 \mathrm{Na}_{2}$-ATP, and $0.4 \mathrm{Na}_{3}$-GTP, pH adjusted to 7.2-7.3 with $\mathrm{KOH}$ (osmolarity to $280 \mathrm{mOsm} / \mathrm{kg}$ with sucrose). After tight ( $>2 \mathrm{G} \Omega$ ) seals were formed and the whole-cell configuration was obtained, neurons were included in the sample if the resting membrane potential (RMP) was more negative than $-50 \mathrm{mV}$ and action potentials overshooting $0 \mathrm{mV}$ were evoked by direct depolarizing current injections.

Voltage and current signals were low-pass filtered at $1 \mathrm{kHz}$ with a dual four-pole Bessel filter (Warner Instruments, Hamden, CT), digitized at 5 $\mathrm{kHz}$ (Digidata 1322A interface; Molecular Devices, Sunnyvale, CA), and stored on a computer (Dell Pentium 4; Dell Computer Company, Round Rock, TX). Data were also continuously recorded on an ink chart recorder (Gould 3400; Gould Instrument Systems, Valley View, OH). Current- and voltage-clamp (discontinuous single-electrode voltage clamp) recordings were made using an Axoclamp-2B amplifier (Molecular Devices) with a switching frequency of $5-6 \mathrm{kHz}$ (30\% duty cycle), gain of $3-8 \mathrm{nA} / \mathrm{mV}$, and time constant of $20 \mathrm{~ms}$. Phase shift and anti-alias filter were optimized. The head-stage voltage was monitored continuously on a digital oscilloscope (Gould 400; Gould Instrument Systems) to ensure precise performance of the amplifier. If series resistance (monitored with pClamp9 software; Molecular Devices) changed $>10 \%$, the neuron was discarded to minimize any potentially confounding influences of series and space clamp changes. Voltage and current data were analyzed with pClamp9 software (Molecular Devices). Neurons were voltage clamped at $-60 \mathrm{mV}$ except for the analysis of inhibitory synaptic transmission (recorded at $-40 \mathrm{mV}$ ).

Synaptic stimulation. Using two concentric bipolar stimulating electrodes (SNE-100, 22 k $\Omega$; David Kopf Instruments, Tujunga, CA), monosynaptic EPSCs were evoked in CeLC neurons by electrical stimulation [using a Grass Instruments (Quincy, MA) S88 stimulator] of two distinct lines of input (see Fig. 1): the PB-CeLC synapse, which contains afferents from the lateral parabrachial area and provides presumed nociceptive input from the spino-parabrachio-amygdaloid pain pathway, and the basolateral amygdala (BLA)-CeLC synapse, which transmits highly integrated polymodal information from thalamic and cortical areas and is part of the fear/anxiety circuitry (Neugebauer et al., 2004; Neugebauer, 2006; Lopez de Armentia and Sah, 2007). For stimulation of the PBCeLC synapse, the electrode was positioned under microscopic control on the afferent fiber tract from the lateral $\mathrm{PB}$, which runs dorsomedial to the CeA and ventral to but outside of the caudate-putamen (Neugebauer et al., 2003; Lopez de Armentia and Sah, 2004, 2007; Bird et al., 2005; Han et al., 2005b; Ikeda et al., 2007). In the vicinity of this tract, no other afferents to the CeA have been described (Schwaber et al., 1988; Harrigan et al., 1994; Alheid et al., 1995).

Electrical stimuli (150 $\mu$ s square-wave pulses) were delivered at low frequencies $(<0.25 \mathrm{~Hz})$. Input-output functions were obtained by increasing the stimulus intensity in $100 \mu \mathrm{A}$ steps. For evaluation of a drug effect on synaptically evoked responses, the stimulus intensity was adjusted to $75-80 \%$ of the intensity required for orthodromic spike generation (Neugebauer et al., 2003; Bird et al., 2005; Han et al., 2005b).

Paired-pulse ratio (PPR) analysis allows to determine presynaptic versus postsynaptic mechanisms in the CNS (McKernan and ShinnickGallagher, 1997) and has been applied successfully to the study of drug effects in the CeLC (Neugebauer et al., 2003; Bird et al., 2005). Two orthodromic synaptic stimuli of equal intensity were applied at varying intervals, and the resulting EPSCs were recorded in whole-cell voltage clamp. Peak amplitudes of the initial EPSC (EPSC1) and the second EPSC (EPSC2) were measured as the difference between the current level before the stimulus artifact and the peak of the EPSC. PPR was calculated as the ratio of EPSC2 over EPSC1 and expressed in percentage. Any alterations in PPR suggest a presynaptic site of action (McKernan and Shinnick-Gallagher, 1997; Neugebauer et al., 2003; Bird et al., 2005). PPR was measured before and during drug application.

Miniature EPSCs and IPSCs. The analysis of miniature events is a well established tool to determine the site of drug actions within a specific synapse (Schrader and Tasker, 1997) and has been used successfully in our previous studies of synaptic transmission in the amygdala (Han et al., 
2004, 2005b, 2006; Bird et al., 2005). Presynaptic changes at the transmitter release site affect frequency, whereas changes at the postsynaptic membrane would alter amplitude (quantal size) of the miniature events (Wyllie et al., 1994). For the recording of miniature EPSCs (mEPSCs) or mIPSCs, tetrodotoxin (TTX) $(1 \mu \mathrm{M})$ was added to the ACSF to block action potential-dependent synaptic transmission. mEPSCs were recorded in the presence of bicuculline $(30 \mu \mathrm{M})$; mIPSCs were isolated pharmacologically with DL-2-amino-5-phosphonopentanoic acid (AP-5) $(50 \mu \mathrm{M})$ and 2,3-dioxo - 6-nitro - 1,2,3,4-tetrahydrobenzo[f] quinoxaline-7-sulfonamide disodium salt (NBQX) $(20 \mu \mathrm{M})$ and were recorded at $-40 \mathrm{mV}$. A fixed length of traces ( $5 \mathrm{~min}$ ) was analyzed for frequency and amplitude distributions of mEPSCs or mIPSCs using MiniAnalysis program 5.3 (Synaptosoft, Decatur, GA). The root mean square (RMS) of the background noise was computed for each set of data. The detection threshold for an event was set to three to four times the RMS value. The peaks were detected automatically, but each detected event was then visually inspected to prevent the inclusion of false data.

Drugs. The following selective CRF receptor antagonists were used. NBI27914 (CRF1 receptor antagonist) (Hoare et al., 2003; Pollandt et al., 2006; Ji and Neugebauer, 2007) was purchased from Tocris Bioscience (Ellisville, MO). Astressin-2B (CRF2 receptor antagonist) (Rivier et al., 2002; Hoare et al., 2005; Pollandt et al., 2006; Ji and Neugebauer, 2007) was a generous gift from Dr. Jean Rivier of The Salk Institute (La Jolla, CA); additional amounts were purchased from Sigma (St. Louis, MO). AP-5 (NMDA receptor antagonist), NBQX (non-NMDA receptor antagonist), bicuculline ([R- $\left.\left(R^{\star}, S^{\star}\right)\right]$-6-(5,6,7,8-tetrahydro-6-methyl-1,3-dioxolo[4,5-g]isoquinolin-5yl)furo[3,4-e]-1,3-benzodioxol-8(6H)-one) ( $\mathrm{GABA}_{\mathrm{A}}$ receptor antagonist), and CGP 35348 [3-aminopropyl)(diethoxymethyl)phosphinic acid] $\left(\mathrm{GABA}_{\mathrm{B}}\right.$ receptor antagonist) (Porter and Nieves, 2004) were purchased from Tocris Bioscience. KT5720, a potent and selective PKA inhibitor (Cabell and Audesirk, 1993; Bird et al., 2005), was purchased from Tocris Bioscience. Drugs were dissolved in ACSF on the day of the experiment and applied to the brain slice by gravity-driven superfusion in the ACSF $(\sim 2 \mathrm{ml} /$ $\mathrm{min})$. Solution flow into the recording chamber ( $1 \mathrm{ml}$ volume) was controlled with a three-way stopcock.

Drugs were applied for at least 15 min to establish equilibrium in the tissue. Based on initial observations showing that drug effects reached a plateau after $10 \mathrm{~min}$, the $12-15 \mathrm{~min}$ time point was selected for the full set of tests (input-output functions, current-voltage relationships, pairedpulse ratio, mEPSC and mIPSC analysis, and action potential firing properties; see above) and for the comparison of drug effects.

\section{Behavior: vocalizations and hindlimb withdrawal reflexes}

Experimental protocol. On day 1, a guide cannula for drug (and ACSF vehicle) application by microdialysis was stereotaxically inserted into the CeLC. Baseline (before arthritis) vocalizations and spinal withdrawal reflexes were measured in normal rats in the afternoon of day 2 . The behavioral tests were repeated in the afternoon of day 3 in the same animals before drug administration (ACSF vehicle control), during drug administration (15 min), and after drug administration (30 min washout with ACSF). Animals tested on day 3 were either normal (no arthritis) or arthritic (6 h after arthritis induction in one knee; see above, Arthritis pain model).

Drug application by microdialysis. As described in detail previously (Han and Neugebauer, 2005; Han et al., 2005b; Ji et al., 2007), rats were anesthetized with pentobarbital sodium $(50 \mathrm{mg} / \mathrm{kg}$, i.p.), and a small unilateral craniotomy was performed at the sutura frontoparietalis level. Using a stereotaxic apparatus (David Kopf Instruments), a guide cannula was implanted on the dorsal margin of the CeLC as described previously in detail (Han and Neugebauer, 2005; Han et al., 2005b), using the following coordinates (Paxinos and Watson, 1998): 1.8-2.0 mm caudal to bregma, $4.0 \mathrm{~mm}$ lateral to midline, $7.0 \mathrm{~mm}$ depth. In some experiments, a guide cannula was implanted into the striatum as a placement control, using the following stereotaxic coordinates: $2.0 \mathrm{~mm}$ caudal to bregma, $4.5 \mathrm{~mm}$ lateral to midline, $5.0 \mathrm{~mm}$ depth of tip. The cannula was fixed to the skull with dental acrylic (Plastics One, Roanoke, VA). Antibiotic ointment was applied to the exposed tissue to prevent infection. On the day of the experiment, a microdialysis probe (CMA/Microdialysis 11; membrane diameter, $250 \mu \mathrm{m}$; membrane length, $1 \mathrm{~mm}$; CMA/Microdi- alysis, Solna, Sweden) was inserted into the CeLC through the guide cannula so that the probe protruded by $1 \mathrm{~mm}$. Using polyethylene- 50 tubing, the probe was connected to a Harvard infusion pump and perfused with ACSF $(2 \mu \mathrm{l} / \mathrm{min}$ ) containing the following (in $\mathrm{mM}$ ): 125.0 $\mathrm{NaCl}, 2.6 \mathrm{KCl}, 2.5 \mathrm{NaH}_{2} \mathrm{PO}_{4}, 1.3 \mathrm{CaCl}_{2}, 0.9 \mathrm{MgCl}_{2}, 21.0 \mathrm{NaHCO}_{3}$, and 3.5 glucose, oxygenated and equilibrated to $\mathrm{pH}$ 7.4. Before each drug application, ACSF was pumped through the fiber for at least $1 \mathrm{~h}$ to establish equilibrium in the tissue.

CRF1 and CRF2 receptor antagonists (see above, Electrophysiology: patch-clamp recording) were dissolved in ACSF on the day of the experiment at a concentration 100 times that predicted to be needed based on published data (Rivier et al., 2002; Hoare et al., 2003, 2005; Pollandt et al., 2006), our previous microdialysis studies (Ji and Neugebauer, 2007; Ji et al., 2007), and our own in vitro data (this study) because of the concentration gradient across the dialysis membrane and diffusion in the tissue (Li and Neugebauer, 2004a,b, 2006; Han et al., 2005b; Ji and Neugebauer, 2007). The numbers given in this article refer to the drug concentrations in the microdialysis fiber. ACSF administered alone served as a vehicle control. Behavior was measured at 15-20 min during continued drug administration and again at $30 \mathrm{~min}$ of washout with ACSF.

Audible and ultrasonic vocalizations. Vocalizations were recorded and analyzed as described in detail previously (Han and Neugebauer, 2005). The experimental setup (U.S. Patent 7,213,538) included a customdesigned recording chamber, a condenser microphone (audible range, $20 \mathrm{~Hz}$ to $16 \mathrm{kHz}$ ) connected to a preamplifier, an ultrasound detector (25 $\pm 4 \mathrm{kHz}$ ), filter and amplifier (UltraVox 4-channel system; Noldus Information Technology, Leesburg, VA), and data acquisition software (UltraVox 2.0; Noldus Information Technology), which automatically monitored the occurrence of vocalizations within user-defined frequencies and recorded number and duration of digitized events (audible and ultrasonic vocalizations). This computerized recording system was set to suppress nonrelevant audible sounds (background noise) and to ignore ultrasounds outside the defined frequency range. Animals were placed in the recording chamber for acclimation $1 \mathrm{~h}$ before the vocalization measurements and for habituation ( $1 \mathrm{~h}$ on $2 \mathrm{~d}$ ). The recording chamber ensured the stable positioning of the animal at a fixed distance from the sound detectors and allowed the reproducible stimulation of the knee joint through openings for the hindlimbs. Brief (15 s) innocuous (100 $\mathrm{g} / 30 \mathrm{~mm}^{2}$ ) and noxious $\left(2000 \mathrm{~g} / 30 \mathrm{~mm}^{2}\right)$ mechanical stimuli were applied to the knee, using a calibrated forceps equipped with force transducer whose output was displayed on a liquid crystal display screen. The chamber also had an opening for drug administration into the amygdala through the microdialysis probe inserted into the implanted guide cannula. The total duration of vocalizations (arithmetic sum of the duration of individual events) were recorded for $1 \mathrm{~min}$, starting with the onset of the mechanical stimulus. Audible and ultrasonic vocalizations reflect supraspinally organized nocifensive and affective responses to aversive stimuli (Borszcz and Leaton, 2003; Neugebauer et al., 2007).

Hindlimb withdrawal reflex. Thresholds of spinal withdrawal reflexes evoked by mechanical stimulation of the knee joint were measured subsequently to the vocalization measurements as described in detail previously (Han et al., 2005a; Neugebauer et al., 2007). Mechanical stimuli of continuously increasing intensity were applied to the knee joint using a calibrated forceps with a force transducer as in the vocalization experiments. Withdrawal threshold was defined as the minimum stimulus intensity that evoked a withdrawal reflex.

\section{Histology}

At the end of each behavioral experiment, the position of the microdialysis probe in the CeLC or striatum (placement control) was confirmed histologically. The brain was removed and submerged in 10\% Formalin. Tissues were stored in $20 \%$ sucrose before they were frozen sectioned at $50 \mu \mathrm{m}$. Sections were stained with Neutral Red, mounted on gel-coated slides, and coverslipped. Lesion sites were plotted on standard diagrams.

\section{Data analysis and statistics}

All averaged values are given as the mean \pm SEM. Statistical significance was accepted at the level $p<0.05$. GraphPad Prism 3.0 software (GraphPad Software, San Diego, CA) was used for all statistical analysis except when noted. 


\section{Electrophysiology}

Input-output functions and PPR were compared using repeatedmeasures two-way ANOVA followed by post hoc tests when appropriate. One-way ANOVA with post hoc tests was used to compare membrane properties of neurons from normal and from arthritic animals and to determine the significance of drug effects on EPSCs and IPSCs when more than one drug was tested. The paired $t$ test was used to compare evoked EPSC or IPSC amplitudes and mean mEPSC or mIPSC amplitudes before and during a single drug application. mEPSCs and mIPSCs were analyzed for frequency and amplitude distributions using the MiniAnalysis program 5.3 (Synaptosoft). The Kolmogorov-Smirnov test was used for statistical analysis of the cumulative distribution of mEPSC and mIPSC amplitude and frequency.

\section{Behavior}

Duration of audible and ultrasonic vocalizations was defined as the arithmetic sum (total amount) of the durations of individual vocalization events in a $1 \mathrm{~min}$ recording period. The paired $t$ test was used to evaluate the significance of drug effects on vocalizations and withdrawal thresholds in the same animal under normal conditions ("normal" group). Newman-Keuls multiple comparison test was used to compare behaviors under normal conditions, in arthritis, and during drug administration in a separate group of animals ("arthritis" group).

\section{Results}

Electrophysiological changes of CeLC neurons in the arthritis pain model

Whole-cell patch-clamp recordings were made of neurons in the CeLC in brain slices from normal rats ( $n=55$ neurons) and from arthritic rats ( $6 \mathrm{~h}$ after induction; $n=43$ neurons). Only one or two brain slices per animal were used, and one neuron was recorded in each slice. The different nuclei of the amygdala and subdivisions of the central nucleus are easily discerned under the microscope (Fig. 1). CeLC neurons in this study were characterized by their convergent inputs from the parabrachial area (PBCeLC synapse) and from the basolateral circuitry (BLA-CeLC) (see Materials and Methods, Synaptic stimulation). Our previous studies showed that neurons with convergent inputs develop pain-related plasticity in vitro and resemble multireceptive neurons that become sensitized in vivo (Neugebauer et al., 2004; Neugebauer, 2006). Based on their action potential firing properties, these neurons were non-accommodating, repetitive and regular spiking, which is the prevalent type of neurons in this division of the amygdala (Schiess et al., 1999; Dumont et al., 2002; Neugebauer et al., 2003; Lopez de Armentia and Sah, 2004, 2007).

In agreement with published data from our group (Neugebauer et al., 2003; Bird et al., 2005; Han et al., 2005b, 2006) and others (Ikeda et al., 2007), enhanced synaptic transmission was recorded in the CeLC in brain slices from arthritic rats compared with control CeLC neurons from normal rats. Enhanced synaptic transmission preserved in the slice preparation indicates "synaptic plasticity" because it is maintained independently of peripheral or spinal mechanisms. Pain-related synaptic plasticity was evident from the increased synaptic strength measured as increased peak amplitudes of monosynaptic EPSCs evoked at the nociceptive PB-CeLC synapse (Fig. $2 B, D$ ) and the polymodal BLA-CeLC synapse (data not shown) (Neugebauer et al., 2004, 2007) in the arthritis pain model (for details of synaptic stimulation, see Materials and Methods). CeLC neurons in slices from arthritic animals also had a significantly more depolarized RMP $(-58.0 \pm 1.1 \mathrm{mV}, n=55$, arthritis; $-61.7 \pm 0.5 \mathrm{mV}, n=43$, normal; $p<0.01$, one-way ANOVA) and decreased input resistance $\left(R_{\mathrm{i}}\right)(193.8 \pm 8.2 \mathrm{M} \Omega$, arthritis; $243.4 \pm$ 5.7, normal; $p<$ 0.01 ) as described previously (Neugebauer et al., 2003; Bird et al., 2005).

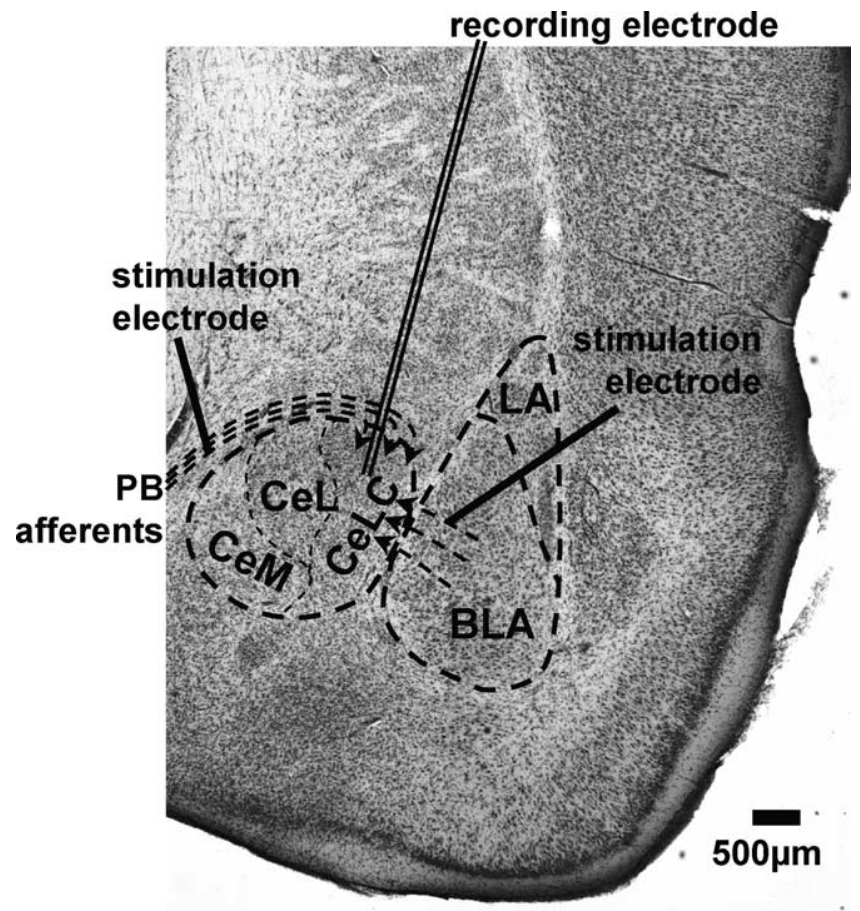

Figure 1. Recording and stimulation sites in amygdala brain slices. The different nuclei of the amygdala and subdivisions of the central nucleus are easily discerned. Stimulation electrodes were positioned in the BLA and on fibers that contained afferents from the PB to stimulate the BLA-CeLC and PB-CeLC synapses, respectively (Neugebauer et al., 2003; Lopez de Armentia and Sah, 2004, 2007; Neugebauer, 2006; Ikeda et al., 2007). The patch electrode was positioned in the CeLC. CeM, CeL, CeLC, Medial, lateral, and laterocapsular divisions of the central nucleus, respectively.

Differential effects of CRF1 and CRF2 receptor antagonists on pain-related synaptic facilitation

Input-output functions of the $\mathrm{PB}-\mathrm{CeLC}$ synapse were measured before and during application of antagonists for CRF1 (NBI27914, $500 \mathrm{~nm}$ ) (Fig. 2A,B) and CRF2 (astressin-2B, 500 nM) (Fig. 2C,D). In brain slices from normal rats (Fig. $2 A, C$ ), the antagonists had no effects on basal synaptic transmission (NBI27914, $n=10$; astressin-2B, $n=5)$. However, in brain slices from arthritic rats (Fig. $2 B, D$ ), NBI27914 inhibited synaptic facilitation significantly $\left(n=10, p<0.0001, F_{(1,99)}=48.55\right.$, repeated-measures two-way ANOVA; GraphPad Prism), whereas astressin-2B further increased synaptic transmission $\left(n=5, p<0.0001, F_{(1,44)}=44.93\right)$.

The normalized results obtained with CRF1 and CRF2 antagonists at the PB-CeLC and BLA-CeLC synapses in the arthritis pain model are summarized in Figure 3. NBI27914 (500 nM) inhibited synaptic facilitation at the PB-CeLC synapse (Fig. 3A) ( $n=10, p<0.001$, paired $t$ test) and at the BLA-CeLC synapse (Fig. $3 B)(n=11, p<0.001)$, whereas astressin-2B facilitated transmission at the PB-CeLC synapse (Fig. $3 C)(n=5, p<0.05$, paired $t$ test) and at the BLA-CeLC synapse (Fig. $3 D)(n=8, p<$ $0.05)$. Synaptic responses were evoked by a stimulus intensity adjusted to $70-80 \%$ of that required for generating the maximum EPSC amplitude. These data suggest that enhanced activation of CRF1 receptors by the endogenous ligand represents an important mechanism of pain-related synaptic facilitation in the amygdala. At the same time, the endogenous activation of CRF2 receptors exerts a latent inhibitory influence. 
A normal

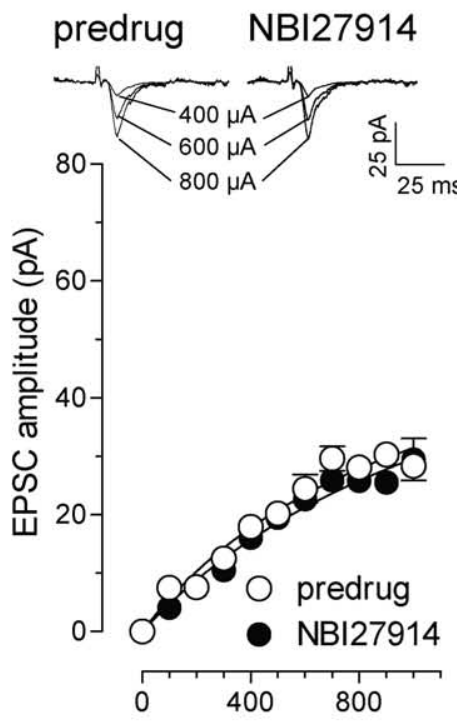

stimulus intensity $(\mu \mathrm{A})$
B arthritis

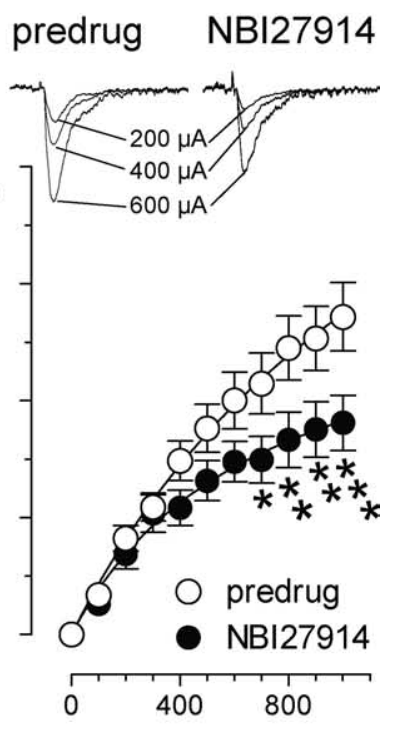

stimulus intensity $(\mu \mathrm{A})$

\section{C normal}

\section{predrug astressin-2B}

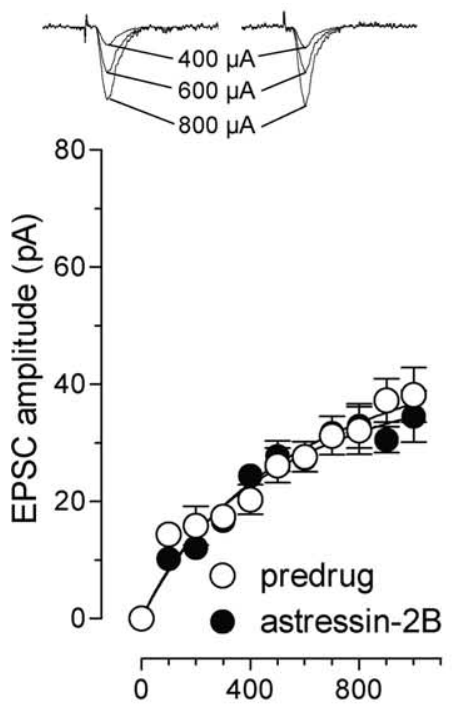

stimulus intensity $(\mu \mathrm{A})$

\section{D arthritis}

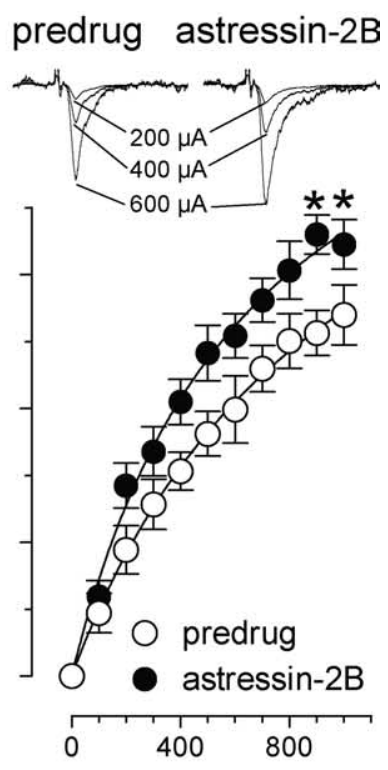

stimulus intensity $(\mu \mathrm{A})$

Figure 2. Increased synaptic transmission in the arthritis pain model is reduced by a CRF1 receptor antagonist but not by a CRF2 receptor antagonist. Input-output functions of the PB-CeLC synapse were obtained by measuring EPSC peak amplitude (picoamperes) as a function of afferent fiber volley stimulus intensity (microamperes) for each neuron. Monosynaptic EPSCs were evoked by electrical stimulation of increasing intensities. Insets show original traces of evoked EPSCS (average of 2-3 EPSCS) at different stimulus intensities. $A-D$, Synaptic transmission was studied in brain slices from normal rats $(\boldsymbol{A}, \boldsymbol{C})$ and from arthritic rats $(\boldsymbol{B}, \boldsymbol{D})$. Inputoutput functions were measured before and during application of antagonists for CRF1 (NBI27914, $500 \mathrm{~nm}, 15 \mathrm{~min} ; \boldsymbol{A}, \boldsymbol{B}$ ) and CRF2 (astressin-2B, $500 \mathrm{~nm}, 15 \mathrm{~min} ; \boldsymbol{C}, \boldsymbol{D}$ ) receptors. The antagonists had no effects under normal conditions (NBI27914, $n=10$; astressin-2B, $n=5$ ). NBI27914 significantly inhibited enhanced synaptic transmission in the arthritis pain model $(n=10)$, whereas astressin-2B had facilitatory effects $(n=5)$. Whole-cell voltage-clamp recordings of CeLC neurons held at $-60 \mathrm{mV} .{ }^{*} p<0.05$, ${ }^{* *} p<0.01$, ${ }^{* * *} p<0.001$ (repeatedmeasures two-way ANOVA followed by Bonferroni's post hoc tests).

\section{NBI27914}
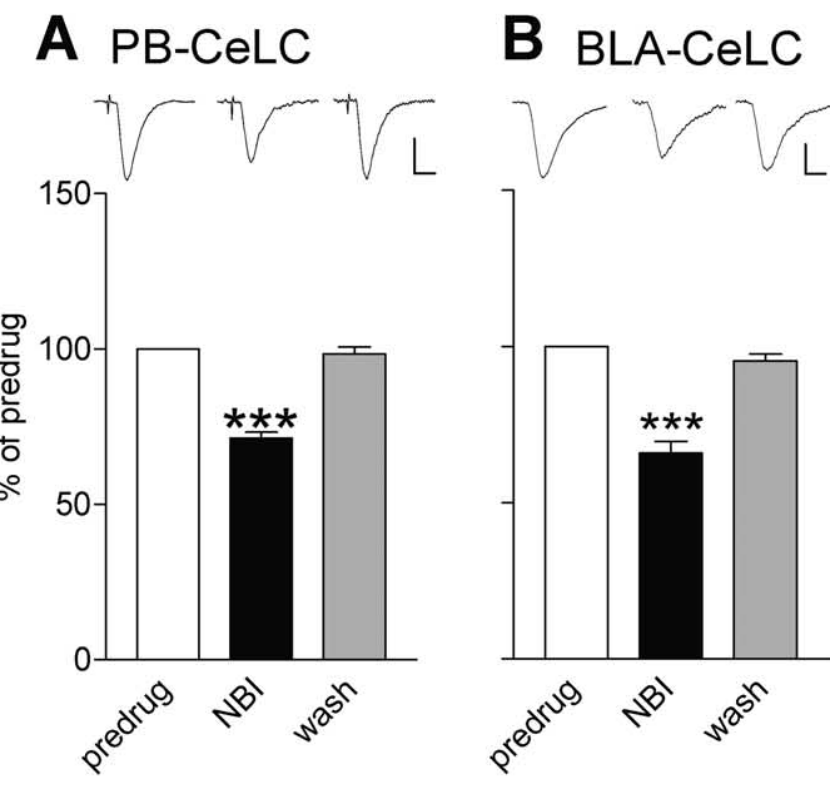

Astressin-2B

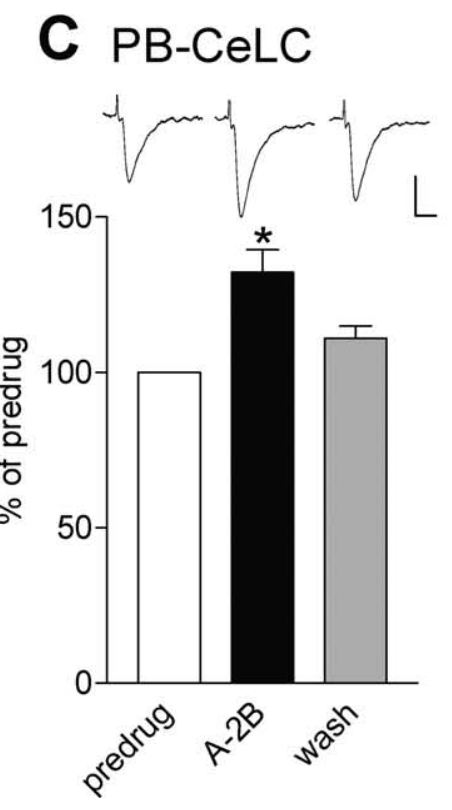

D BLA-CelC

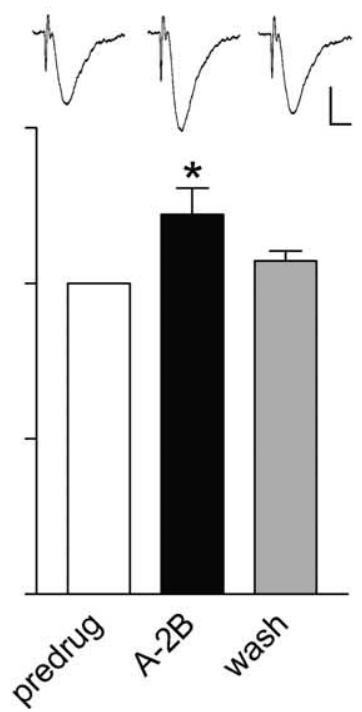

Figure 3. $\quad \boldsymbol{A}-\boldsymbol{D}$, Normalized results obtained with CRF1 and CRF2 antagonists at the PB-CeLC and BLA-CeLC synapses in the arthritis pain model. NBI27914 (NBI, $500 \mathrm{~nm}, 15 \mathrm{~min}$ ) inhibited synaptic facilitation at both synapses ( $\boldsymbol{A}, \mathrm{PB}-\mathrm{CeLC}, n=10 ; \boldsymbol{B}, \mathrm{BLA}-\mathrm{CeLC}, n=11$ ), whereas astressin-2B (A-2B, $500 \mathrm{~nm}, 15 \mathrm{~min}$ ) facilitated transmission (C, PB-CeLC, $n=5 ; \mathbf{D}, \mathrm{BLA}-\mathrm{CeLC}$, $n=8$ ). Synaptic responses were evoked by a stimulus intensity adjusted to $70-80 \%$ of that required for generating the maximum EPSC amplitude. Insets show original traces of evoked EPSCS (average of $8-10$ ) before, during, and after (15 min wash) drug application. Calibration: $50 \mathrm{pA}, 10 \mathrm{~ms}$. Whole-cell voltage-clamp recordings of CeLC neurons held at $-60 \mathrm{mV}$. ${ }^{*} p<$ $0.05,{ }^{* * *} p<0.001$ (paired $t$ test).

\section{Differential mechanisms of CRF1 and CRF2} receptor function

Next we sought to determine whether the differential effects of CRF1 and CRF2 antagonists in the CeLC were attributable to different sites and modes of action. The results show for the first time that, in the arthritis pain model, postsynaptic CRF1 recep- 
tors enhance NMDA receptor function through a PKAdependent mechanism, whereas presynaptic CRF2 receptors increase GABAergic transmission.

\section{Presynaptic versus postsynaptic sites of action}

To assess whether the CRF1 and CRF2 receptor antagonists act on presynaptic or postsynaptic sites in the CeLC, we used a number of well established electrophysiological methods, including quantal analysis of mEPSCs (see Figs. $4 A, B, 5 A, B$ ) and PPR (see Figs. $4 C, 5 C$ ). These parameters were measured before and during application of the antagonists in amygdala brain slices from arthritic rats (the antagonists had no effects under normal conditions).

The analysis of amplitude and frequency distribution of mEPSCs in the presence of TTX can be used to determine presynaptic versus postsynaptic mechanisms. Presynaptic changes at the transmitter release site affect mEPSC frequency, whereas changes at the postsynaptic membrane alter mEPSC amplitude (quantal size) (Wyllie et al., 1994; Han et al., 2004, 2005b). Blockade of CRF1 receptors decreased the amplitude, but not frequency, of mEPSCs recorded in CeLC neurons $(n=4)$ in slices from arthritic rats (Fig. $4 A, B)$. NBI27914 (500 nM) caused a shift of the cumulative mEPSC amplitude distribution toward smaller amplitudes ( $p<0.01$, Kolmogorov-Smirnov test) (Fig. $4 A$ ) and decreased the mean mEPSC amplitude significantly $(p<0.05$, paired $t$ test) (Fig. $4 A$, bar histogram). The effects of NBI27914 were reversible after washout for 15-20 min. NBI27914 had no effect on the frequency of mEPSCs (cumulative interevent interval distribution, $p>0.05$, Kolmogorov-Smirnov test; mean mEPSC frequency, $p>0.05$, paired $t$ test) (Fig. $4 B$ ).

In contrast, blockade of $\mathrm{CRF} 2$ receptors increased the frequency, but not amplitude, of mEPSCs recorded in CeLC neurons $(n=5)$ in slices from arthritic rats (Fig. $5 A, B)$, suggesting a presynaptic mechanism. Astressin-2B shifted the cumulative interevent interval distribution toward shorter intervals $(p<0.05$, Kolmogorov-Smirnov test) (Fig. $5 B$ ), thus increasing the mean frequency significantly ( $p<0.05$, paired $t$ test) (Fig. $5 B$, bar histogram). The effects of astressin-2B were reversible after washout for $20 \mathrm{~min}$. Astressin-2B had no effect on the mEPSC amplitude distribution ( $p>0.05$, Kolmogorov-Smirnov test) (Fig. $5 A$ ) and mean mEPSC amplitude ( $p>0.05$, paired $t$ test) (Fig. $5 A$, bar histogram).

Next, we used another measure of presynaptic mechanisms, PPR. Any changes in PPR suggest a presynaptic site of action (McKernan and Shinnick-Gallagher, 1997; Neugebauer et al., 2003; Bird et al., 2005; Han et al., 2005b). PPR was calculated as the ratio of the second and the first of two consecutive EPSCs evoked at the BLA-CeLC and PB-CeLC synapses by two electrical stimuli of equal intensity at increasing interstimulus intervals (Figs. $4 C, D, 5 C, D)$. PPR was studied only in brain slices from arthritic rats because the antagonists had no effects on synaptic transmission under normal conditions (Fig. 2). NBI27914 (500 $\mathrm{nM}$ ) had no significant effect on PPR at various interstimulus intervals (BLA-CeLC, $n=5, p>0.05, F_{(1,20)}=1.79$; PB-CeLC, $n=5, p>0.05, F_{(1,20)}=0.06$, repeated-measures two-way ANOVA) (Fig. $4 C, D)$, arguing against a presynaptic action. In contrast, astressin-2B (500 nM) significantly decreased the PPR at the BLA-CeLC synapse $\left(n=5, p<0.001, F_{(1,20)}=18.81\right.$, repeated-measures two-way ANOVA with Bonferroni's post hoc tests) (Fig. $5 C)$ and at the PB-CeLC synapse $(n=5, p<0.05$, $F_{(1,20)}=5.02$ ) (Fig. 5D). The effects of astressin-2B were reversible after washout for $20 \mathrm{~min}$.

Together, the results from the analysis of mEPSCs and PPR
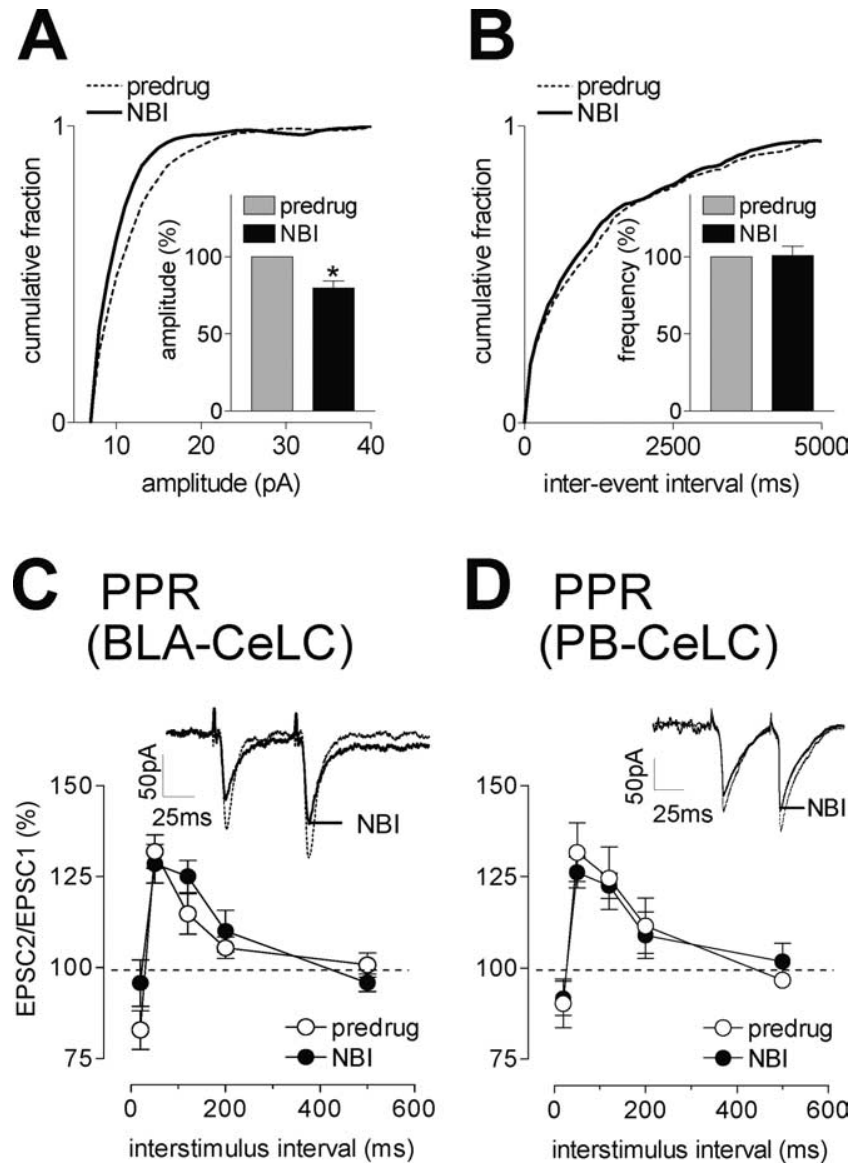

Figure 4. Evidence for postsynaptic effects of a CRF1 receptor antagonist. Analysis of mEPSC amplitude $(\boldsymbol{A})$ and frequency $(\boldsymbol{B})$ in the presence of TTX (1 $\mu \mathrm{m})$ and bicuculline $(30 \mu \mathrm{m})$ showed that NBI27914 (NBI, $500 \mathrm{~nm}$ ) significantly reduced the cumulative amplitude distribution ( $p<$ 0.01 , Kolmogorov-Smirnov test; $\boldsymbol{A}$ ) and mean amplitude ( $p<0.05$, paired $t$ test; $\boldsymbol{A}$, bar histogram; $n=4$ ) but not interevent interval distribution ( $p>0.05$, Kolmogorov-Smirnov test; $\boldsymbol{B}$ ) and mean frequency (events per second; $p>0.05$, paired $t$ test; $\boldsymbol{B}$, bar histogram; $n=$ 4). $C, D$, The PPR, a measure of presynaptic mechanisms, was not changed by NBI27914 (500 nM). PPR was calculated as the ratio of the second and the first of two consecutive EPSCs evoked at the BLA-CeLC synapse by two electrical stimuli of equal intensity at increasing interstimulus intervals. Peak EPSC amplitudes were measured as the difference between the current level before the stimulus artifact and the peak of the EPSC. NBI27914 had no significant effect on the PPR ratio at various stimulus intervals at the BLA-CeLC $(n=5)$ and PB-CeLC synapse $(n=5$, $p>0.05$, repeated-measures two-way ANOVA), further arguing against a presynaptic action. Insets show current traces (average of 8-10 EPSCs) recorded in an individual CeLC neuron to illustrate that PPR (50 ms stimulus interval) was not affected by NBI27914. Symbols and error bars represent mean $\pm \mathrm{SE}(\boldsymbol{A}-\boldsymbol{D})$. Neurons were recorded in voltage clamp at $-60 \mathrm{mV}$ in slices from arthritic rats ( $6 \mathrm{~h}$ after induction). ${ }^{*} p<0.05$.

suggest that the endogenous CRF1 receptor activation occurs at a postsynaptic site in CeLC neurons, whereas CRF2 receptor activation is presynaptic.

\section{Modulation of glutamatergic versus GABAergic transmission}

Our previous studies showed that postsynaptic NMDA receptor activation though a PKA-dependent mechanism plays a critical role in arthritis pain-related synaptic plasticity in the CeLC (Bird et al., 2005). Furthermore, PKA activation in CeLC neurons results at least in part from the activation of neuropeptide receptors that couple to the activation of adenylyl cyclase, such as the calcitonin gene-related peptide receptor CGRP1 (Han et al., 2005b). Both CRF1 and CRF2 receptors are known to couple to the activation of the CAMP-PKA signaling pathway (Dautzenberg and Hauger, 2002; Reul and Holsboer, 2002; Blank et al., 2003; Hoare 

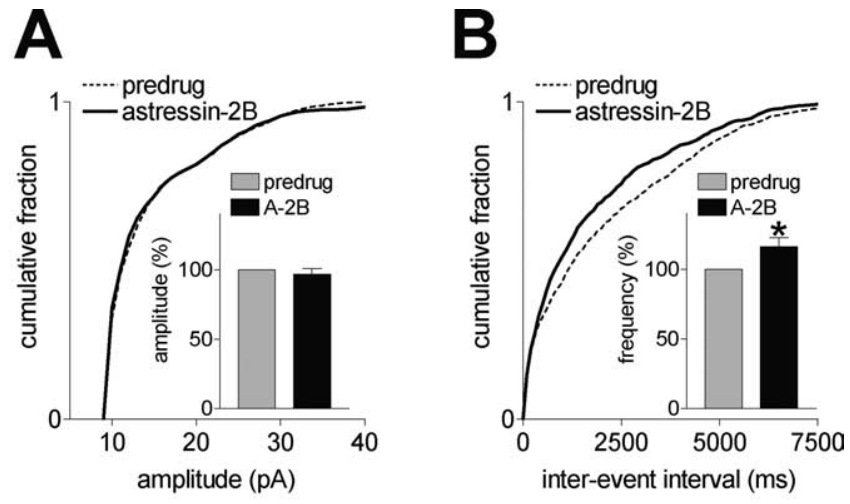

C PPR (BLA-CeLC)

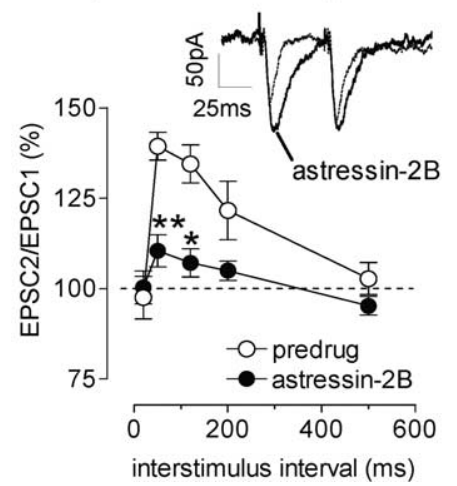

D PPR (PB-CeLC)

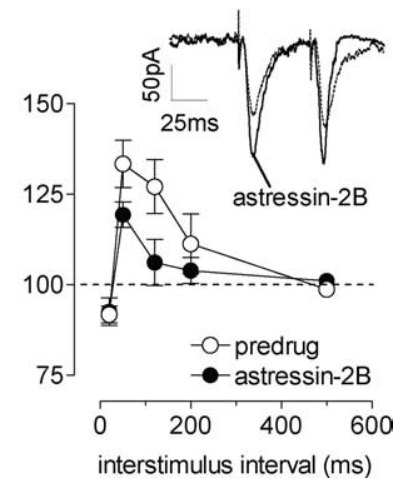

Figure 5. Evidence for presynaptic effects of a CRF2 receptor antagonist. Analysis of $m E P S C$ amplitude $(\boldsymbol{A})$ and frequency $(\boldsymbol{B})$ in the presence of TTX $(1 \mu \mathrm{M})$ and bicuculline $(30 \mu \mathrm{m})$. Astressin- $2 B(A-2 B, 500 \mathrm{~nm})$ significantly shifted the cumulative interevent interval distribution toward shorter intervals ( $p<0.05$, Kolmogorov-Smirnov test; $\boldsymbol{B}$ ) and increased the mean frequency (events per second; $p<0.05$, paired $t$ test; $\boldsymbol{B}$, bar histograms; $n=5$ ). Astressin- $2 B$ had no significant effect on the cumulative amplitude distribution ( $p>0.05$, KolmogorovSmirnov test; $A$ ) and mean amplitude ( $p>0.05$, paired $t$ test; $A$, bar histograms; $n=5)$. C, $\boldsymbol{D}$, PPR, a measure of presynaptic mechanisms, was decreased by astressin- $2 B(500 \mathrm{~nm})$ at the BLA-CeLC synapse ( $n=5, p<0.001$, repeated-measures two-way ANOVA) and the PB-CeLC synapse $(n=5, p<0.05)$. PPR was calculated as described in Figure 4. Insets show current traces (average of $8-10$ EPSCS) recorded in an individual CeLC neuron to demonstrate that there was no PPR at the 50 ms interstimulus interval in the presence of astressin-2B. A-D, CeLC neurons were recorded at $-60 \mathrm{mV}$ in slices from arthritic rats ( $6 \mathrm{~h}$ after induction). ${ }^{*} p<0.05$, ${ }^{* *} p<0.01$.

et al., 2003, 2005; Arzt and Holsboer, 2006). Because CRF1 receptors act postsynaptically to facilitate synaptic transmission (see results of this study), we tested the hypothesis that the endogenous activation of CRF1 receptors modulates PKA-dependent NMDA receptor function.

NBI27914 (500 nM) inhibited the pharmacologically (with NBQX, $20 \mu \mathrm{M}$ ) isolated NMDA receptor-mediated synaptic component in the arthritis pain model (Fig. $6 \mathrm{~A}$, individual example; $C$, summary). The NMDA receptor-mediated EPSC was also reduced by a selective membrane-permeable PKA inhibitor (KT5720, $1 \mu \mathrm{M}$ ) (Fig. 6B, individual example; 6C, summary) as in our previous studies (Bird et al., 2005; Han et al., 2005b). In the presence of the PKA inhibitor, NBI27914 produced no additional inhibition (Fig. $6 B$, individual example; $C$, summary), suggesting that CRF1 receptor activation requires PKA, because the effects of NBI27914 were occluded by the PKA inhibitor. These experiments were done only in slices from arthritic animals because NBI27914 had no effect on basal synaptic transmission in slices
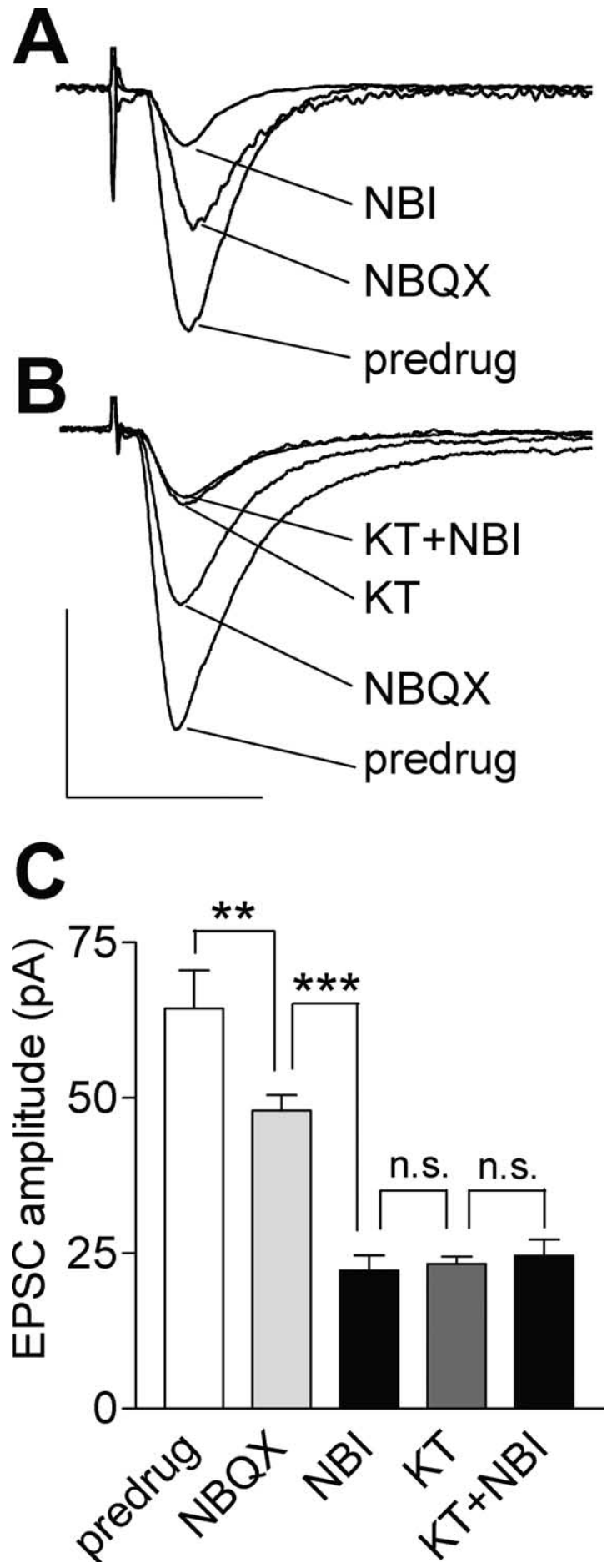

Figure 6. Inhibition of NMDA receptor-mediated synaptic facilitation by a CRF1 receptor antagonist is occluded by a PKA inhibitor. A, NBI27914 (500 nM) inhibited the pharmacologically isolated NMDA receptor-mediated synaptic component. Monosynaptic EPSCs (average of 8-10 traces) recorded in an individual CeLC neuron in a brain slice from an arthritic rat were inhibited by NBQX (20 $\mu \mathrm{M})$ and further reduced by NBI27914 in the continued presence of NBQX. B, A selective membranepermeable PKA inhibitor (KT5720, $1 \mu \mathrm{m}$ ) also reduced the NMDA receptor-mediated EPSC and occluded the effect of NBI27914. Monosynaptic EPSCS (average of 8-10traces) recorded in an individual CeLC neuron in a brain slice from an arthritic rat were inhibited by NBQX and further reduced by KT5720. Coapplication of NBI27914 with KT5720 had no additional effects (in the continued presence of NBQX). C, Summary of the significant inhibition of synaptic facilitation (peak EPSC amplitude) by $\operatorname{NBQX}(n=4)$ and NBI27914 $(n=4)$. The inhibitory effects of NBI27914 and KT5720 $(n=4)$ were not significantly different from each other. Coapplication of NBI27914 and KT5720 $(n=4)$ did not produce an additional effect. Calibration: $50 \mathrm{pA}, 25 \mathrm{~ms} .{ }^{* *} p<0.01,{ }^{* * *} p<0.001$ (ANOVA followed by Newman-Keuls multiple comparison test). 
from normal animals (Fig. 2). Furthermore, our previous studies showed that NMDA receptors and PKA do not contribute to basal synaptic transmission under normal conditions (Bird et al., 2005; Han et al., 2005b). These data suggest that the endogenous activation of postsynaptic CRF1 receptors contributes to arthritis pain-related synaptic facilitation through increased PKA-dependent NMDA receptor function.

CRF2 receptors also couple to the cAMP-PKA signaling pathway, but they mediate effects opposite to those of CRF1 receptors (Figs. 2, 3) and are presynaptic. Therefore, we hypothesized that a CRF2 receptor antagonist produced its facilitatory effects through disinhibition, i.e., presynaptic inhibition of inhibitory GABAergic transmission. In slices from arthritic animals, astressin-2B (500 nM) inhibited the pharmacologically isolated (with NBQX, $20 \mu \mathrm{M}$ and AP-5, $50 \mu \mathrm{M}$ ) IPSC that was evoked in CeLC neurons by electrical stimulation in the BLA $(n=6)$ (Fig. $7 A)$. The IPSC was GABAergic because it was blocked with bicuculline $(30 \mu \mathrm{M})$. In contrast, NBI27914 (500 nM) had no effect on the evoked IPSC $(n=5)$ (Fig. $7 B)$. Analysis of pharmacologically isolated (with NBQX, $20 \mu \mathrm{M}$ and AP-5, $50 \mu \mathrm{M}$ ) mIPSCs in the presence of TTX $(1 \mu \mathrm{M})$ showed that astressin-2B decreased the frequency but not amplitude (Fig. 7C-E), suggesting a presynaptic site of action. Astressin-2B had no effect on mIPSC amplitude distribution ( $n=5, p>0.05$, KolmogorovSmirnov test) (Fig. 7D) and mean mIPSC amplitude (bar histogram). However, astressin-2B shifted the cumulative interevent interval distribution toward longer intervals $(n=5, p<0.01$, KolmogorovSmirnov test) (Fig. $7 E$ ), thus decreasing the mean frequency significantly $(p<$ 0.001, Dunnett's multiple comparison test; bar histogram). The mIPSCs were significantly blocked by bicuculline (30 $\mu \mathrm{M} ; p<0.001$, Dunnett's multiple comparison test) (Fig. $7 D, E$, bar histograms).

Next we measured the effects of astressin-2B on excitatory and inhibitory transmission in slices from arthritic rats while blocking either postsynaptic $\mathrm{GABA}_{\mathrm{A}}$ receptors with bicuculline or presynaptic $\mathrm{GABA}_{\mathrm{B}}$ receptors with CGP35348 (Olpe et al., 1990; Pitler and Alger, 1994; Deisz et al., 1997; Porter and Nieves, 2004). GABA $\mathrm{B}$ receptors can serve as presynaptic heteroreceptors on glutamatergic terminals in which they inhibit voltagedependent $\mathrm{Ca}^{2+}$ channels and thus presynaptic calcium influx to decrease glutamate release (Misgeld et al., 1995; Wu and Saggau, 1997; Porter and Nieves, 2004; Potes et al., 2006). We hypothesized that presynaptic CRF2 receptors on GABAergic terminals increase GABAergic inhibitory transmission. As a consequence, postsynaptic $\mathrm{GABA}_{\mathrm{A}}$ receptor-mediated IPSCs increase, whereas EPSCs are decreased by presynaptic $\mathrm{GABA}_{\mathrm{B}}$ receptor activation on glutamatergic terminals. Bicuculline $(30 \mu \mathrm{M})$ affected neither
EPSCs nor the ability of astressin-2B ( $500 \mathrm{nM}$ ) to facilitate EPSCs (Fig. 8A). IPSCs were blocked by bicuculline and astressin-2B had no additional effect (Fig. $8 \mathrm{~B}$ ). Blockade of $\mathrm{GABA}_{\mathrm{B}}$ receptors with CGP35348 $(100 \mu \mathrm{M})$ increased EPSCs (Fig. $8 C$ ) and occluded the facilitatory effect of astressin-2B (500 nM), suggesting the involvement of $\mathrm{GABA}_{\mathrm{B}}$ receptors in the modulation of EPSCs by CRF2 receptors. CGP35348 had no effect on IPSCs (Fig. $8 D$ ), arguing against a role of $\mathrm{GABA}_{\mathrm{B}}$ autoreceptors. In the presence of CGP35348, astressin-2B continued to depress IPSCs (Fig. 8D), which is consistent with the involvement of CRF2 receptors on GABAergic terminals.

These results suggest that blockade of presynaptic CRF2 receptors by astressin-2B decreases $\mathrm{GABA}_{\mathrm{A}}$ receptor-mediated inhibitory transmission and increases excitatory transmission through the decreased activation of presynaptic $\mathrm{GABA}_{\mathrm{B}}$ receptors that regulate glutamate release. In contrast, postsynaptic CRF1 receptors activate PKA to increase NMDA receptor-mediated transmission. 


\section{$\mathrm{GABA}_{\mathrm{A}}$ receptor blockade}
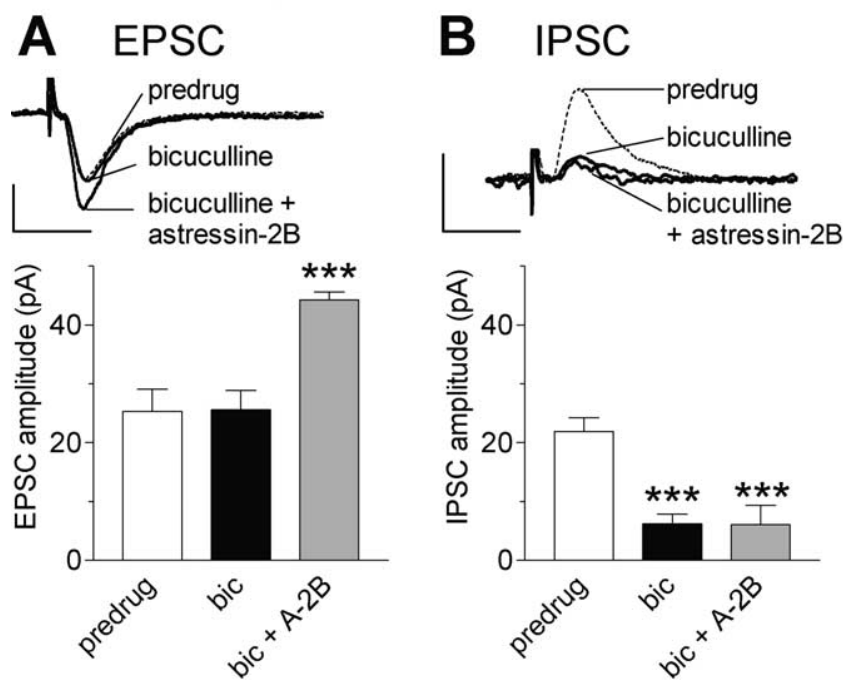

$\mathrm{GABA}_{\mathrm{B}}$ receptor blockade

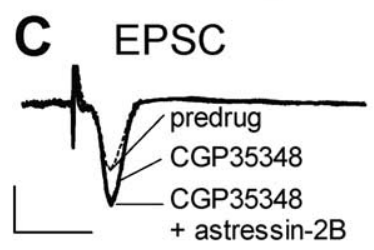

D IPSC
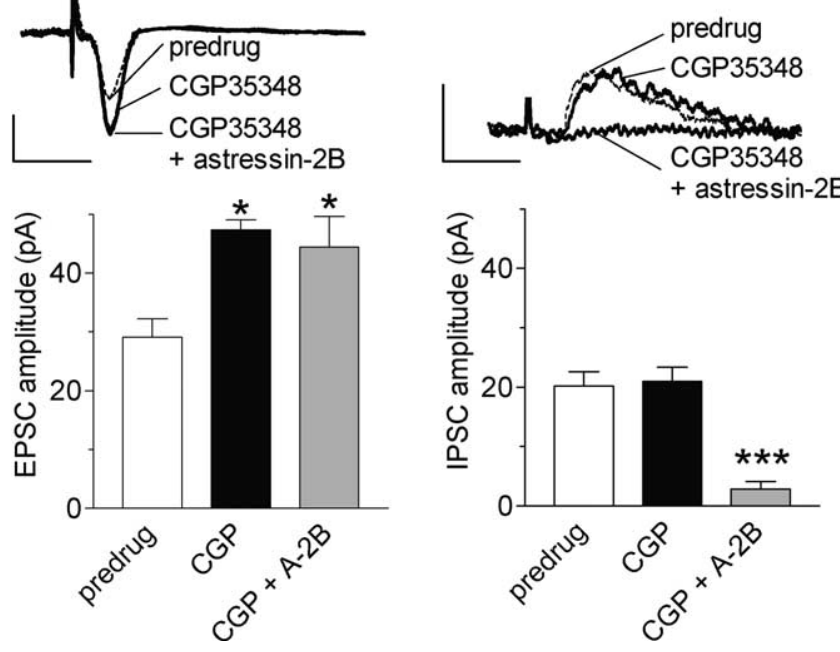

Figure 8. $\boldsymbol{A}-\boldsymbol{D}$, Contribution of $\mathrm{GABA}_{A}$ and $G A B A_{B}$ receptors to $C R F 2$ receptor-mediated effects on excitatory and inhibitory synaptic transmission. EPSCS ( $A, \boldsymbol{C})$ and IPSCS $(\boldsymbol{B}, \boldsymbol{D})$ evoked at the BLA-CeLC synapse were recorded in slices from arthritic animals ( $6 \mathrm{~h}$ after induction). $A$, In the presence of bicuculline $(30 \mu \mathrm{m})$ to block $\mathrm{GABA}_{\mathrm{A}}$ receptors, astressin- $2 \mathrm{~B}(500 \mathrm{~nm})$ continued to facilitate EPSCS $(n=3, p<0.001)$. $B$, IPSCs were blocked by bicuculline administered alone or together with astressin-2B ( $n=3, p<0.001)$. C, A GABA $A_{B}$ receptor antagonist (CGP35348, $100 \mu \mathrm{M})$ alone or together with astressin-2B increased EPSCs significantly $(n=3$, $p<0.05)$. D, CGP35348 had no effect on IPSCs. In the presence of CGP35348, astressin-2B continued to depress IPSCS $(n=3, p<0.001)$. Original traces are averages of $8-10$ EPSCs or IPSCs. EPSCs were recorded at $-60 \mathrm{mV}$; IPSCs were recorded at $-40 \mathrm{mV}$. Calibration: $25 \mathrm{pA}, 25$ ms. ${ }^{*} p<0.05,{ }^{* * *} p<0.001$ (compared with predrug controls; Dunnett's multiple comparison test).

\section{CRF1, but not CRF2, receptors modulate neuronal} excitability through highly TEA-sensitive ion channels

The effects of CRF1 and CRF2 receptor antagonists on neuronal excitability were determined by measuring the action potential firing rate, duration (spike width), and decay time. Action potentials were evoked in current-clamp mode by direct intracellular current injections of increasing magnitude through the patch electrode (50 pA steps, $500 \mathrm{~ms}$ ). Recordings were performed at $-60 \mathrm{mV}$. Input-output functions of neuronal excitability were obtained by averaging the frequency of action potentials evoked at each current intensity as in our previous studies (Neugebauer et al., 2003; Bird et al., 2005; Han et al., 2005b). NBI27914 (500 $\mathrm{nM})$ significantly decreased the input-output function of CeLC neurons from arthritic rats $\left(n=8, p<0.0001, F_{(1,56)}=174.67\right.$, repeated-measures two-way ANOVA) (Fig. 9A). The slowing of action potential firing was accompanied by a broadening of the action potential measured as increased duration (spike width) and longer decay time ( $n=8, p<0.05$, paired $t$ test) (Fig. 9B). In slices from normal animals, neither NBI27914 $(n=5)$ nor astressin-2B $(n=5)$ had a significant effect on the input-output functions of neuronal excitability $\left(p>0.05, F_{(1,32)}=0.46\right.$ and 1.27 , respectively, repeated-measures two-way ANOVA) and on action potential kinetics ( $p>0.05$, paired $t$ test).

A number of ionic mechanisms are involved in spike broadening during repetitive firing, including several types of $\mathrm{K}^{+}$currents (Martina et al., 1998; Erisir et al., 1999; Rudy et al., 1999; Faber and Sah, 2003). Published data (Martina et al., 1998; Erisir et al., 1999; Rudy et al., 1999; McKay and Turner, 2004) suggest that blockade of $\mathrm{K}^{+}$channels containing subunits of the Kv3 family is most likely to account for spike broadening and reduced firing frequency as observed with the CRF1 receptor antagonist in the present study (Fig. 9A,B). Kv3 channels, which are expressed in the amygdala, including the CeA (McDonald and Mascagni, 2006), can be distinguished pharmacologically because of their high sensitivity to extracellular TEA (Martina et al., 1998; Erisir et al., 1999; Rudy et al., 1999; Sacco et al., 2006). Blockade of other known $\mathrm{K}^{+}$channels that are sensitive to TEA would be expected to produce opposite or no effects on spike firing (Erisir et al., 1999; Rudy and McBain, 2001; Faber and Sah, 2003; Kasten et al., 2007).

Therefore, we studied the effect of a very low concentration of extracellular TEA $(50 \mu \mathrm{M})$ on action potential firing frequency and spike shape to determine whether inactivation of a highly TEA-sensitive ion channel could account for the effects of blocking CRF1 receptors with NBI27914. TEA produced a reduction of the steady repetitive firing rate, thereby decreasing the inputoutput function of neuronal excitability $\left(p<0.001, n=3, F_{(1,16)}\right.$ $=71.02$, repeated-measures two-way ANOVA) (Fig. 9C). TEA also increased spike width and decay time $(p<0.01$, repeatedmeasures ANOVA followed by Newman-Keuls multiple comparison test) (Fig. 9D). In the presence of TEA, NBI27914 had no additional effects (Fig. 9C,D), suggesting that NBI27914 and TEA act through a common mechanism. Astressin-2B ( $500 \mathrm{nM}, n=6)$ had no effect on neuronal excitability (Fig. 9E) and action potential kinetics (Fig. 9F), further arguing against a postsynaptic membrane site of action of CRF2 receptors. Neither NBI27914 nor astressin-2B changed the resting membrane potential, input resistance, and capacitance.

\section{Differential effects of CRF1 and CRF2 receptor antagonists on pain behaviors}

To validate the significance of the endogenous CRF1 and CRF2 receptor activation observed in the electrophysiological studies, we analyzed the effects of CRF1 and CRF2 antagonists on supraspinally (vocalizations) and spinally (hindlimb withdrawal reflexes) organized pain behavior in awake animals (Fig. 10). The antagonists were administered into the lateral/laterocapsular divisions of the CeA (CeLC) by microdialysis in two groups of animals: normal animals without arthritis $(n=11)$ and arthritic animals ( $6 \mathrm{~h}$ postinduction of arthritis, $n=17$ ). In each group, pain behaviors were measured before (in ACSF), during (15-20 min), and after (30 min washout) drug administration. In the 

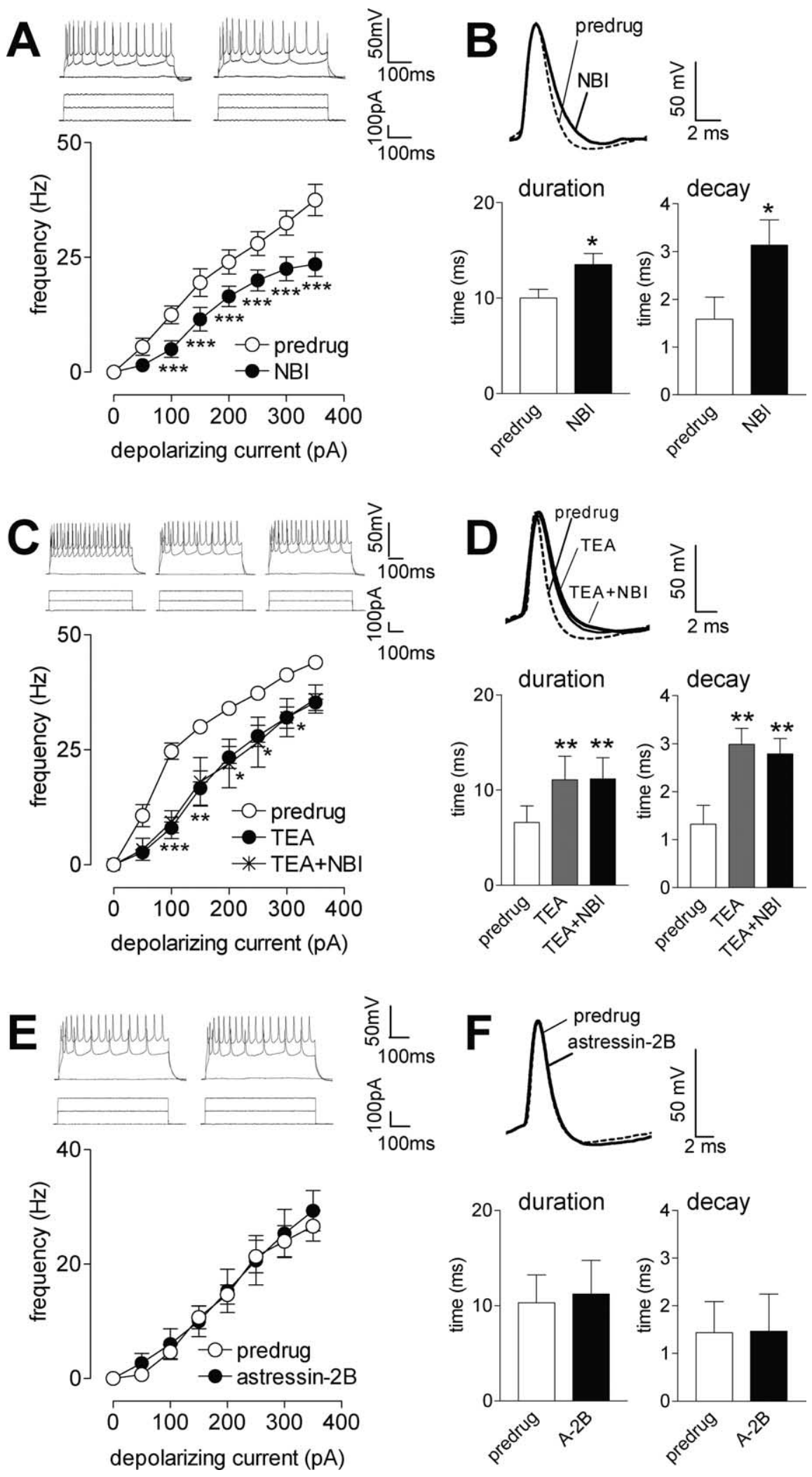

Figure 9. CRF1, but not CRF2, receptors modulate neuronal excitability though $\mathrm{K}^{+}$channels. Action potentials were evoked in current-clamp mode by direct intracellular current injections of increasing magnitude through the patch electrode (50 pA steps, $500 \mathrm{~ms}$ ) at a holding potential $-60 \mathrm{mV}$. Input-output functions of neuronal excitability were obtained by averaging the frequency of action potentials evoked at each current intensity (Neugebauer et al., 2003; Bird et al., 2005; Han et al., 2005b). $\boldsymbol{A}$, $\mathrm{NBI} 27914$ (NBI, $500 \mathrm{~nm}$ ) significantly decreased the input- output function of CeLC neurons in slices from arthritic rats $(n=8, p<$ $0.0001, F_{(1,56)}=174.67$, repeated-measures two-way ANOVA followed by Bonferroni's post hoc tests). $B, N B I 27914$ also increased the spike duration (spike width) and decay time ( $n=8, p<0.05$, paired $t$ test). $\boldsymbol{C}, \boldsymbol{D}$, A very low concentration of the $\mathrm{K}^{+}$-channel blocker TEA $(50 \mu \mathrm{m})$ decreased the input- output function of CeLC neurons from arthritic rats $(\boldsymbol{C} ; p<0.001, n=3$, arthritis group, pain behaviors were also measured the day before arthritis induction to obtain baseline controls. Drugs were administered into the right CeA contralateral to the arthritis because of the strong contralateral projection of the spino-parabrachio-amygdaloid pain pathway (Gauriau and Bernard, 2002) and published data showing that the right $\mathrm{CeA}$ is the site of pain-related plasticity and pain modulation (Neugebauer et al., 2004; Neugebauer, 2006; Carrasquillo and Gereau, 2007). All animals had guide cannulas for the microdialysis probes implanted on the day before the behavioral tests.

Vocalizations

Audible $(<16 \mathrm{kHz}$ ) (Fig. 10A,B) and ultrasonic $(25 \pm 4 \mathrm{kHz})$ (Fig. 10C,D) vocalizations evoked by noxious stimuli represent supraspinally organized nocifensive and affective responses, respectively (for details, see Han and Neugebauer, 2005; Neugebauer et al., 2007). As in our previous studies (Han and Neugebauer, 2005; Han et al., 2005a,b; Neugebauer et al., 2007; Ji et al., 2007), the total duration of audible and ultrasonic vocalizations increased in rats with arthritis compared with the baseline vocalizations of the same animals under normal conditions (arthritis CRF1 group, $n=11$; arthritis CRF2 group, $n=6$; $p<0.01-0.001$, NewmanKeuls multiple comparison test) (Fig. $10 A-D)$. Vocalizations were evoked by brief (15 s) noxious (2000 g/30 $\mathrm{mm}^{2}$ ) stimulation of the knee with a calibrated forceps. NBI27914 (50 $\mu \mathrm{M}$, concentration in microdialysis probe; $15-20 \mathrm{~min}$ ) inhibited the increased audible and ultrasonic vocalizations in arthritic rats $(p<0.01-$ 0.001, Newman-Keuls multiple comparison test) but had no significant effect on baseline vocalizations of normal animals without arthritis (normal CRF1 group, $n=5$; arthritis CRF1 group, $n=11$ ) (Fig. $10 \mathrm{~A}, \mathrm{C})$. Astressin-2B (50 $\mu \mathrm{M}$, concentration in microdialysis fiber; $15-20 \mathrm{~min}$ ) had no effect on vocalizations of normal ani-

\footnotetext{
$\leftarrow$

$F_{(1,16)}=71.02$, repeated-measures two-way ANOVA followed by Bonferroni's post hoc tests) and increased spike width and decay time $(\boldsymbol{D} ; p<0.01$, repeated-measures ANOVA followed by Newman-Keuls multiple comparison test). NBI27914 coapplied with TEA had no additional effect, suggesting that NBI27914 and TEA act through a common mechanism such as inhibition of Kv3 channels (see Results). $\boldsymbol{E}$, $\boldsymbol{F}$, Astressin-2B (A-2B, $500 \mathrm{~nm})$ had no effect on neuronal excitability $(E ; n=6, p>0.05$, repeated-measures two-way ANOVA) and action potential kinetics $(\boldsymbol{F} ; n=6, p>0.05$, paired $t$ test), which is consistent with a presynaptic rather than postsynaptic site of action. ${ }^{*} p<0.05,{ }^{* *} p<0.01$, ${ }^{* * *} p<0.001$.
} 


\section{Audible vocalizations}

A CRF1

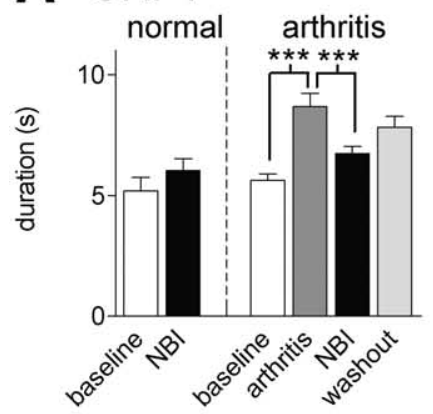

B CRF2

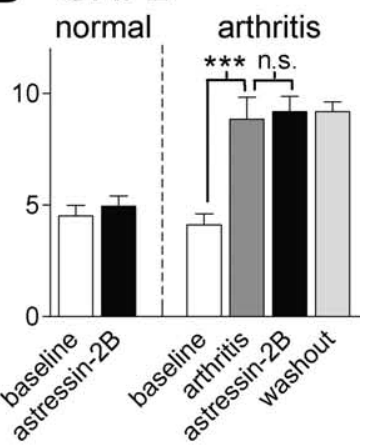

\section{Ultrasonic vocalizations}

\section{CRF1}

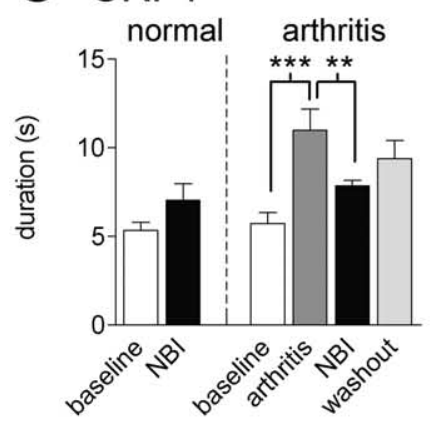

D CRF2

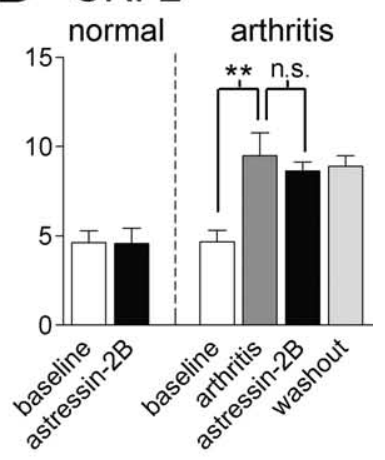

\section{Spinal reflex}
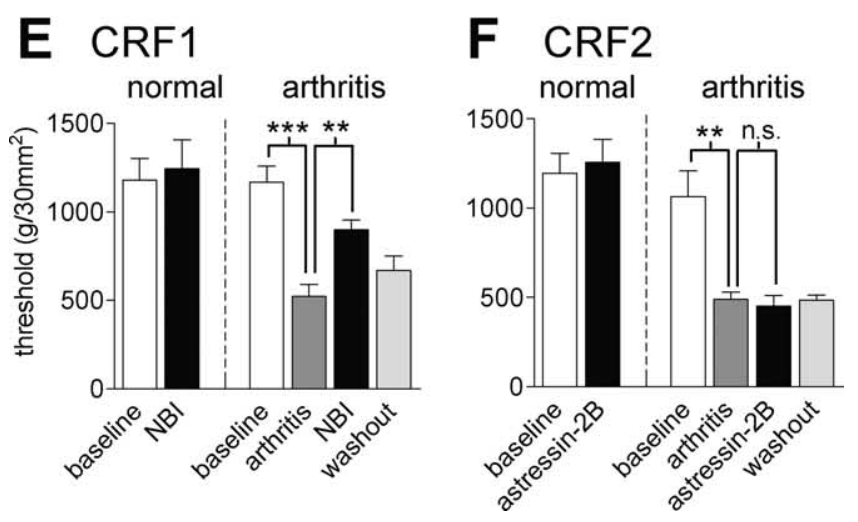

Figure 10. $\quad A C R F 1$, but not $C R F 2$, receptor antagonist inhibits pain-related behavior in animals with arthritis but not in normal animals. Audible $(\boldsymbol{A}, \boldsymbol{B})$ and ultrasonic $(\boldsymbol{C}, \boldsymbol{D})$ vocalizations and spinal withdrawal reflexes $(\boldsymbol{E}, \boldsymbol{F})$ were measured in two groups of animals: normal (left side in each graph) and arthritis (right side). In the normal group, behaviors were measured before (baseline) and during ( $15-20 \mathrm{~min}$ ) drug application into the CeA by microdialysis. In the arthritis group, behaviors were measured before (baseline) and $6 \mathrm{~h}$ after arthritis induction and during (15-20 min) and after (30 min washout) drug application into the CeLC in the arthritis state. Vocalizations were evoked by brief (15 s) noxious $\left(2000 \mathrm{~g} / 30 \mathrm{~mm}^{2}\right)$ stimulation of the knee with a calibrated forceps. Duration of vocalizations was measured as the arithmetic sum of the duration of each individual vocalization event during a 1 min period beginning with the onset of the mechanical stimulus as described previously (Han et al., 2005a; Neugebauer et al., 2007). A, NBI27914 (NBI, $50 \mu \mathrm{m}$, concentration in the microdialysis fiber) had no effect on audible vocalizations in normal animals $(n=5)$ but inhibited the increased vocalizations of arthritic rats significantly ( $n=11, p<0.001$, Newman-Keuls multiple comparison test). $\boldsymbol{B}$, Astressin- $2 B$ ( $50 \mu \mathrm{m}$, concentration in the microdialysis probe) did not affect audible vocalizations in normal rats $(n=6)$ and in arthritic rats $(n=6)$. C, NBI27914 had no significant effect on ultrasonic vocalizations of normal rats $(n=5)$ but inhibited the increased ultrasonic vocalizations of arthritic rats ( $n=11, p<0.01$, Newman-Keuls multiple comparison test). $\boldsymbol{D}$, Astressin-2B had no significant effect on ultrasonic vocalizations of normal rats $(n=6)$ and arthritic rats $(n=6)$. $\boldsymbol{E}$, NBI27914 had no significant effect on hindlimb-withdrawal reflex mals and arthritic animals (normal CRF2 group, $n=6$; arthritis CRF2 group, $n=6$ ) (Fig. 10B,D). Drug concentrations were based on concentration-response data obtained with the microdialysis technique in our previous electrophysiological in vivo study (Ji and Neugebauer, 2007). Drug effects were primarily reversible after 30 min washout with ACSF.

Spinal nocifensive reflexes

Hindlimb withdrawal reflex thresholds were measured by applying pressure of increasing force to the knee joint with a calibrated forceps. Withdrawal thresholds of arthritic rats were significantly lower than baseline thresholds measured in the same animals before arthritis induction (arthritis CRF1 group, $n=11$; arthritis CRF2 group, $n=6$; $p<0.01-0.001$, Newman-Keuls multiple comparison test) (Fig. 10E,F). NBI27914 increased the hindlimb withdrawal thresholds in arthritic rats, partially reversing the mechanical hypersensitivity (arthritis CRF1 group, $n=11, p<0.01$, Newman-Keuls multiple comparison test) (Fig. 10 E). NBI27914 had no significant effect under normal conditions (normal CRF1 group, $n=5$ ) (Fig. 10E). Astressin-2B had no significant effect in arthritic animals $(n=6)$ and under normal conditions $(n=6$, CRF2 groups) (Fig. 10F).

\section{Placement controls}

Drug administration into the striatum had no effects on painrelated behavior in animals with arthritis (Fig. 11). The striatum was chosen as a control site for drug diffusion because it is adjacent (dorsolateral) to the CeLC but does not project to the CeA/ CeLC. The distance between the tips of the microdialysis probes in the CeLC and striatum is $\sim 2 \mathrm{~mm}$. We used this placement control successfully in our previous studies (Han and Neugebauer, 2005; Han et al., 2005b). Rats with arthritis (6 h after induction) showed significantly increased audible (Fig. 11 A,B) and ultrasonic (Fig. 11C,D) vocalizations and significantly decreased hindlimb withdrawal thresholds (Fig. 11E,F) compared with the baseline values measured in the same animals before arthritis ( $n=4, p<0.01-0.05$, Newman-Keuls multiple comparison test). Neither NBI27914 (50 $\mu \mathrm{M}$, concentration in the microdialysis probe; $15-20 \mathrm{~min})$ nor astressin-2B $(50 \mu \mathrm{M})$ had any significant effect on audible (Fig. $11 A, B$ ) and ultrasonic (Fig. $11 C, D$ ) vocalizations and on spinal reflexes (Fig. $11 E, F$ ).

The positions of the microdialysis probes in the CeLC and striatum (caudate-putamen) were verified histologically (Fig. 12). Our data suggest that the endogenous activation of CRF1, but not CRF2, receptors in the amygdala contributes to increased spinal and supraspinal pain behaviors in the arthritis model.

\section{Discussion}

The novel results of this study are as follows. Enhanced endogenous activation of CRF1 receptors in CeLC neurons contributes to pain-related synaptic facilitation in the amygdala. In contrast, endogenous CRF2 receptor activation exerts a latent inhibitory influence that is uncovered with a CRF2 receptor antagonist (Fig. 13). The analysis of mEPSCs and PPR suggests that endogenous CRF1 receptor activation occurs at a postsynaptic site, whereas CRF2 receptor activation is presynaptic. CRF2 receptors increase postsynaptic $\mathrm{GABA}_{\mathrm{A}}$ receptor-mediated inhibitory transmission

$\leftarrow$

thresholds in normal rats but increased the withdrawal thresholds of arthritic rats $(n=11, p<$ 0.01 , Newman-Keuls multiple comparison test). $\boldsymbol{F}$, Astressin-2B had no significant effect in arthritic animals $(n=6)$ and under normal conditions $(n=6)$. Hindlimb-withdrawal thresholds were measured by applying pressure of increasing force to the knee joint with a calibrated forceps. Bar histograms and error bars represent mean \pm SE. ${ }^{* *} p<0.01,{ }^{* * *} p<0.001$. 
Audible vocalizations

\section{A CRF1 B CRF2}
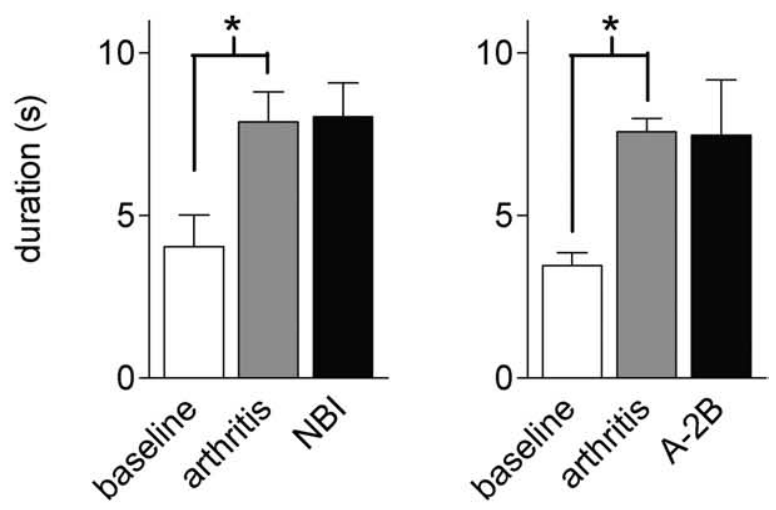

\section{Ultrasonic vocalizations}

\section{CRF1}

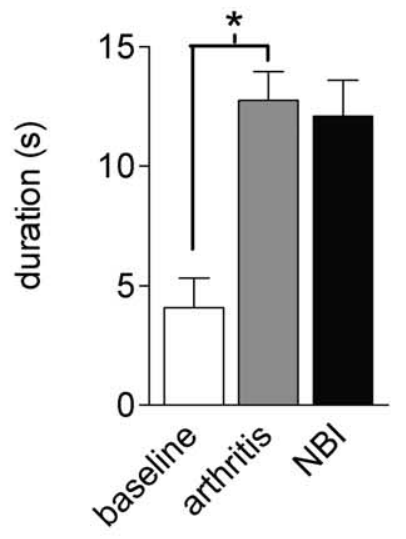

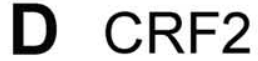

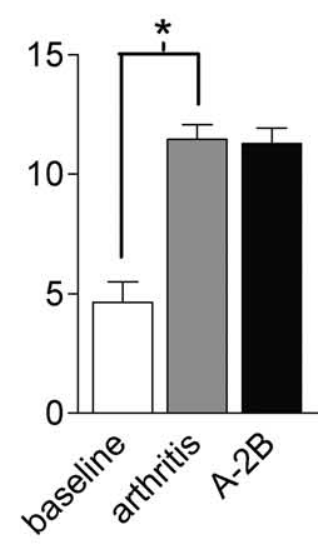

\section{Spinal reflex}

\section{E CRF1}
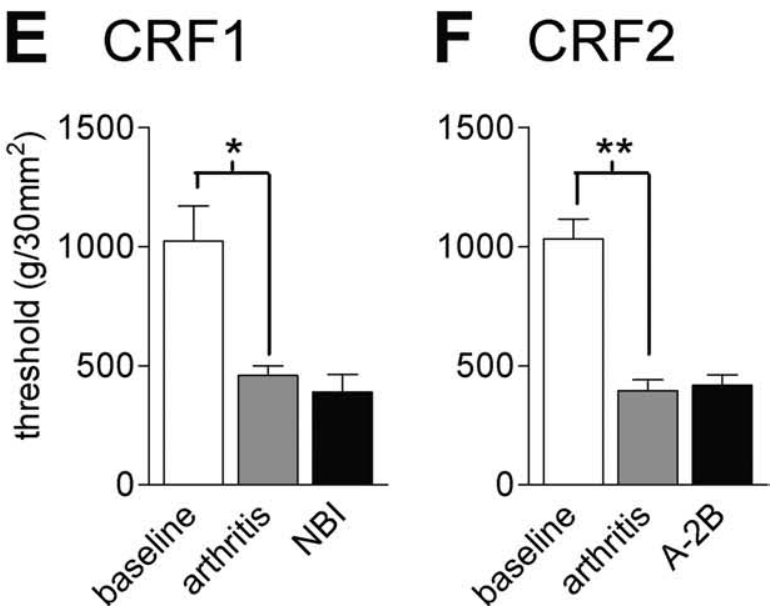

Figure 11. Placement controls. Drug administration into the striatum had no effect on painrelated behavior in animals with arthritis. Audible $(\boldsymbol{A}, \boldsymbol{B})$ and ultrasonic $(\boldsymbol{C}, \boldsymbol{D})$ vocalizations and spinal withdrawal reflexes $(\boldsymbol{E}, \boldsymbol{F})$ were measured before (baseline) and $6 \mathrm{~h}$ after arthritis induction and during (15-20 min) drug application into the striatum in the arthritis state. Vocalizations were evoked by brief $(15 \mathrm{~s})$ noxious $\left(2000 \mathrm{~g} / 30 \mathrm{~mm}^{2}\right)$ stimulation of the knee with a calibrated forceps. Duration of vocalizations was measured as in Figure 10. Hindlimbwithdrawal thresholds were measured by applying pressure of increasing force to the knee joint to the CeLC and presynaptic $\mathrm{GABA}_{\mathrm{B}}$ receptor-mediated inhibition of excitatory transmission. Postsynaptic CRF1 receptors increase the NMDA receptor-mediated synaptic component through a PKA-dependent mechanism. Our antagonist data suggest tonic activation of CRF1 receptors in the arthritis pain model by an endogenous ligand that is continuously released, possibly as the consequence of plastic changes in presynaptic metabotropic glutamate receptor (mGluR) expression and function (Neugebauer et al., 2003). mGluRs can regulate CRF release (Joanny et al., 1997). Reversal of PKA-mediated changes by a CRF1 receptor antagonist or a PKA inhibitor likely involves "net" dephosphorylation attributable to normal phosphatase activity in the absence of continued phosphorylation. Low concentrations of TEA occlude the inhibitory effects of a CRF1 receptor antagonist on neuronal excitability, suggesting that CRF1 receptors can activate a highly TEA-sensitive channel involved in action potential repolarization such as Kv3-type potassium channels. Kv3 channels are characterized by a particularly high TEA sensitivity and by their ability to increase rather than decrease spike firing frequency and excitability (Martina et al., 1998; Rudy et al., 1999). CRF2 receptors are not involved in the modulation of neuronal excitability of CeLC neurons. The consequence of the endogenous activation of CRF1, but not CRF2, receptors in the CeLC is increased spinally and supraspinally organized pain behavior.

Some methodological aspects of this study need to be considered. The results were obtained with receptor antagonists rather than agonists for the following reasons. Antagonists uncover the effects of the endogenous receptor ligand (agonist). The goal of the present study was to determine the role of endogenous receptor activation by the synaptically released ligand. Selective CRF1 and CRF2 receptor antagonists are now available (Rivier et al., 2002; Hoare et al., 2003, 2005; Arzt and Holsboer, 2006), whereas the selectivity of CRF1 agonists such as ovine CRF (oCRF) is marginal, particularly for endogenously expressed receptors as opposed to cloned receptors expressed in transfected cells (Hoare et al., 2005). The very recently described CRF1 agonist stressin-1A is more selective but less potent than oCRF (Rivier et al., 2007). Even the CRF2-selective agonist urocortin 2 has full agonist activity at CRF1 receptors (Hoare et al., 2005). Finally, exogenously administered agonists may act through different mechanisms and sites than synaptically released endogenous ligand(s).

Another issue concerns the use of microdialysis for drug application in our behavioral studies. Microdialysis offers several advantages, including continued drug delivery and steady-state levels without a volume effect (Stiller et al., 2003). However, the dose delivered by microdialysis is not known. Concentrationresponse analysis of CRF1 and CRF2 receptor antagonists in our previous microdialysis study (Ji and Neugebauer, 2007) and the comparison with our in vitro experiments in brain slices using concentrations derived from amygdala studies (Liu et al., 2004; Pollandt et al., 2006) allowed us to estimate that the effective

with a calibrated forceps. Audible $(\boldsymbol{A}, \boldsymbol{B})$ and ultrasonic $(\boldsymbol{C}, \boldsymbol{D})$ vocalizations increased significantly and hindlimb withdrawal thresholds $(\boldsymbol{E}, \boldsymbol{F})$ decreased significantly after arthritis induction ( $p<0.01-0.05$, Newman-Keuls multiple comparison test). $\boldsymbol{A}, \boldsymbol{C}, \boldsymbol{E}, \mathrm{NBI} 27914$ (NBI, 50 $\mu \mathrm{M}$, concentration in the microdialysis fiber) had no effect on audible $(n=4)$ and ultrasonic $(n=4)$ vocalizations and on withdrawal reflexes $(n=4) . \boldsymbol{B}, \boldsymbol{D}, \boldsymbol{F}$, Astressin- $2 \mathrm{~B}(\mathrm{~A}-2 \mathrm{~B}, 50 \mu \mathrm{M}$, concentration in the microdialysis probe) had no effect on audible $(n=4)$ and ultrasonic ( $n=$ 4) vocalizations and on withdrawal reflexes $(n=4)$. All drug effects were reversible after 30 min washout with ACSF. Bar histograms and error bars represent mean \pm SE. ${ }^{*} p<0.05$, ${ }^{* *} p<0.01$. 


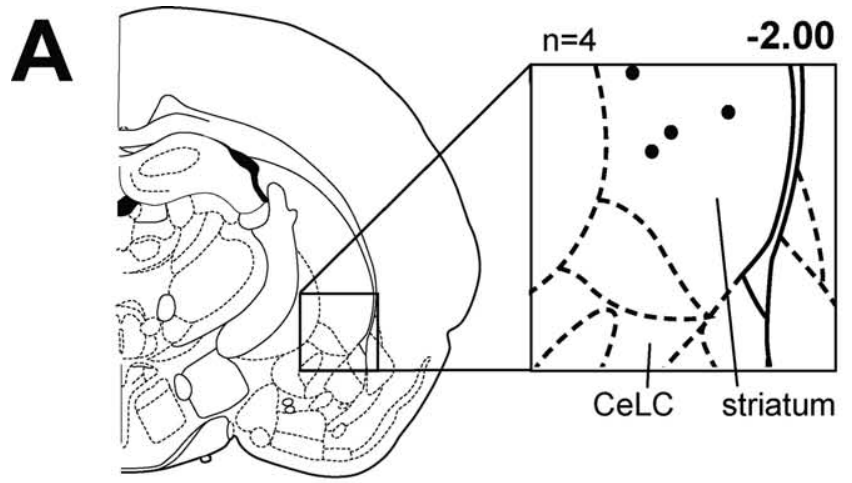

B

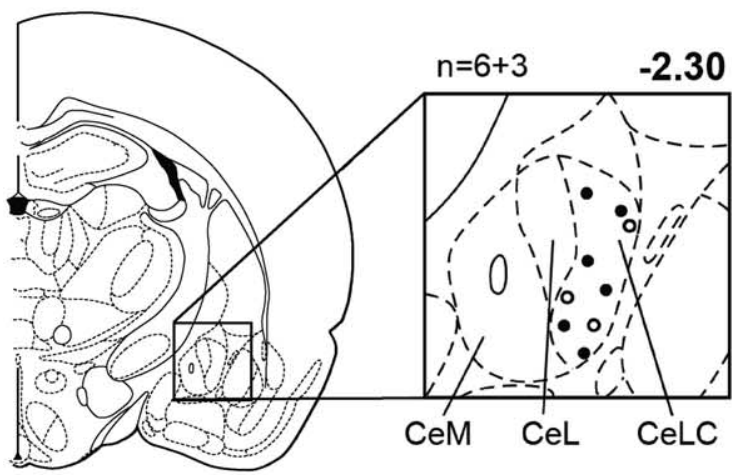

C

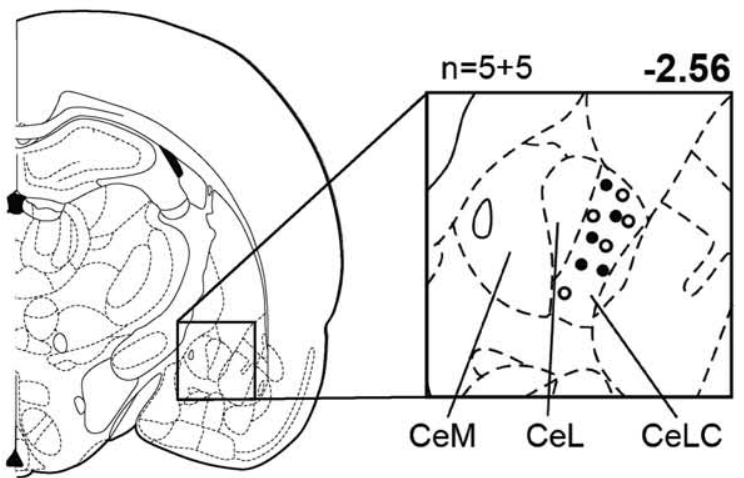

D

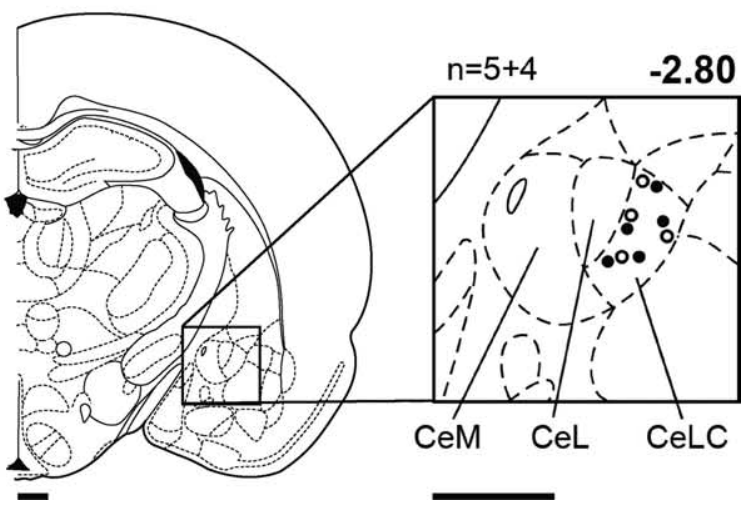

Figure 12. Histologic verification of drug application sites. $\boldsymbol{A}-\boldsymbol{D}$, Standard diagrams (adapted from Paxinos and Watson, 1998) show coronal sections through the right brain hemisphere at different levels posterior to bregma $(-2.00$ to $-2.80 \mathrm{~mm})$. Symbols show the positions of the microdialysis membrane in the striatum ( $\boldsymbol{A}$, placement control) and central nucleus of the amygdala $(\boldsymbol{B}-\boldsymbol{D})$ in the behavioral experiments. Filled circles, Application sites of NBI27914; open circles, astressin-2B. The number of lesion sites $(n)$ for NBI27914 and astressin$2 \mathrm{~B}$, respectively, is indicated above each diagram. CeM, CeL, CeLC, medial, lateral, and laterocapsular divisions of the central nucleus of the amygdala. Calibration bars: $1 \mathrm{~mm}$.

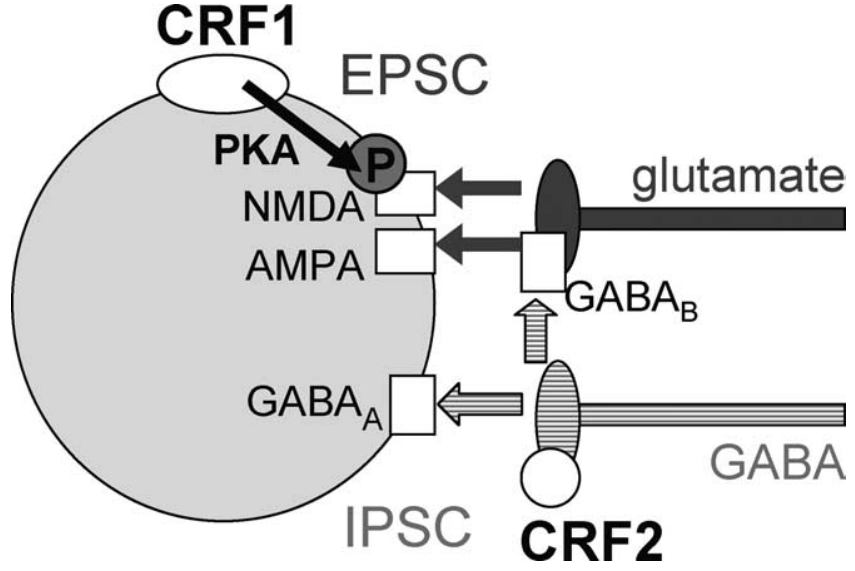

Figure 13. Modulation of synaptic facilitation by CRF1 and CRF2 receptors in the arthritis pain model. CRF1 receptor activation occurs at a postsynaptic site and increases NMDA receptor function through a PKA-dependent mechanism. Pain-related increased NMDA but not nonNMDA (AMPA) receptor function involving PKA, but not PKC, was shown previously (Bird et al., 2005). Presynaptic CRF2 receptors increase $G A B A$ release to activate postsynaptic $G A B A_{A}$ receptors on CeLC neurons and presynaptic $G A B A_{B}$ receptors on glutamatergic terminals. The consequence is increased inhibitory transmission and decreased excitatory transmission to the CeLC. CRF2 receptors are not involved in the modulation of neuronal excitability of CeLC neurons. The consequence of CRF1, but not CRF2, receptor activation in the CeLC is increased pain behavior in the arthritis model.

tissue concentration was in the nanomolar range. The comparison of in vivo and in vitro data confirmed that the drug concentration in the microdialysis fiber needed to be 100 times higher than the desired tissue concentration (see Materials and Methods) (Han et al., 2005b; Ji and Neugebauer, 2007; Ji et al., 2007). Differential effects of CRF1 and CRF2 receptor antagonists in our present and previous studies (Ji and Neugebauer, 2007) argue against nonselective drug effects at the concentrations used. The lack of behavioral effects of astressin-2B is unlikely attributable to an insufficient concentration because the same concentration produced electrophysiological effects in our previous study also using microdialysis (Ji and Neugebauer, 2007). The astressin-2B effect at the single-cell level may not be sufficient to translate into behavioral effects.

The literature on pain-related functions of CRF receptors in the CNS, including the amygdala, is controversial. The majority of older studies found no effect of centrally (intracerebroventricularly) administered CRF. Some studies observed antinociceptive effects in phasic pain tests in normal animals, one study reported hyperalgesic effects, and a few studies observed excitatory effects in several brain areas (Lariviere and Melzack, 2000). A recent study (Vit et al., 2006) showed antinociceptive effects of CRF (intracerebroventricularly) on paw-withdrawal thresholds and on the interphase of the Formalin test, but CRF also increased the number of audible vocalizations (no ultrasonic vocalizations were detected). A nonselective antagonist (astressin) had pronociceptive effects. An increasing number of studies suggest that CRF1 receptors mediate pronociceptive effects of CRF, whereas CRF2 receptors serve antinociceptive functions (Gue et al., 1997; Million et al., 2003, 2006; Martinez et al., 2004; Tache et al., 2004; Greenwood-Van Meerveld et al., 2005; Nijsen et al., 2005). The amygdala has been implicated in the centrally mediated pronociceptive effects of CRF. Microinjections of a nonselective CRF receptor antagonist into the CeA reversed opiate withdrawal-induced hyperalgesia measured in the tail-flick test (McNally and Akil, 2002). A CRF1-selective antagonist inhibited the increased visceromotor responses of rats with stereotaxic de- 
livery of corticosterone to the CeA (Myers et al., 2005). CRF mRNA expression in the CeA increased in models of colitis pain (Greenwood-Van Meerveld et al., 2006) and neuropathic pain (Ulrich-Lai et al., 2006).

Our data suggest that different receptors mediate the divergent effects of CRF in the amygdala, although both CRF1 and CRF2 receptors couple to similar signal transduction mechanisms, typically activating cAMP-PKA signaling (Dautzenberg and Hauger, 2002; Reul and Holsboer, 2002; Blank et al., 2003; Arzt and Holsboer, 2006). Postsynaptic CRF1 receptors increase NMDA receptor function through a PKA-dependent mechanism and activate highly TEA-sensitive channels that accelerate action potential repolarization. A very low concentration of TEA (50 $\mu \mathrm{M})$ broadened the spike and decreased the firing rate, occluding the effects of NBI27914, suggesting the contribution of a highly TEA-sensitive channel involved in action potential repolarization such as Kv3-type channels. Kv3 channels are blocked by low concentrations of TEA, and their blockade decreases the firing rate while broadening the spike (Rudy et al., 1999; Sacco et al., 2006). In contrast, blockade of other known $\mathrm{K}^{+}$channels that could be affected by low TEA (although unlikely at $50 \mu \mathrm{M}$ ) produced opposite or no effects (Erisir et al., 1999; Rudy and McBain, 2001; Faber and Sah, 2003; Kasten et al., 2007). Kv3 channels are expressed in the amygdala, including the CeA (McDonald and Mascagni, 2006), but it is not known whether they are expressed by the specific neuronal subpopulation studied here.

Arthritis pain-related synaptic plasticity in the CeLC depends on normally "silent" NMDA receptors that become functional through NR1 phosphorylation that depends on PKA but not PKC (Li and Neugebauer, 2004a; Bird et al., 2005). The present study suggests that CRF1 receptors can "switch on" NMDA receptors through a PKA-dependent mechanism. The involvement of NR1 phosphorylation remains to be determined in biochemical assays. Phosphorylation relieves the magnesium block (Chen and Huang, 1992), rendering the channel functional even at $-60 \mathrm{mV}$ (Bird et al., 2005). NMDA receptor phosphorylation also accelerates the rise and decay times of the ion channel (Chen and Roche, 2007), which explains the absence of apparent differences in the kinetics of compound EPSCs and NMDA receptormediated EPSCs in the present study. Interestingly, CRF1 receptors in the amygdala mediate the facilitatory effects of CRF at the lateral amygdala-CeA synapse through a PKA-dependent increase of NMDA receptor function in a model of chronic cocaine withdrawal (Pollandt et al., 2006). CRF1 receptor-mediated facilitation of synaptic transmission and neuronal excitability in the present study are consistent with the contribution of CRF1 receptors to the enhanced responsiveness of amygdala neurons in the arthritis pain state (Ji and Neugebauer, 2007).

CRF also modulates inhibitory transmission in the amygdala (BLA) through a mechanism that involves NMDA receptors and calcium/calmodulin-dependent kinase II, but the receptor type remains to be determined (Rainnie et al., 2004). Our data suggest that the endogenous activation of presynaptic CRF2 receptors increases inhibitory transmission to the CeLC in the arthritis pain model but does not modulate neuronal excitability and pain behavior. These results are in agreement with our electrophysiological study in the whole animal that failed to detect effects of astressin-2B on the responses of amygdala neurons after arthritis induction (Ji and Neugebauer, 2007). With regard to CRF2 receptor function under normal conditions, there is some discrepancy between our previous in vivo study in which astressin-2B increased neuronal responsiveness (Ji and Neugebauer, 2007) and the present ex vivo slice experiments that showed no effect of astressin-2B. Contributing factors are differences between both preparations regarding the availability of endogenous ligands from extra-amygdaloid sources, the presence of well documented cortical inhibition of the amygdala (Quirk and Gehlert, 2003; Likhtik et al., 2005), barbiturate anesthesia, and the activation state of the powerful inhibitory network between BLA and CeA (Pare et al., 2004; Woodruff and Sah, 2007). CRF2 receptor blockade would unmask the tonic inhibition that is present in the nonpain state in the anesthetized animal and may require intact extra-amygdaloid inputs.

In conclusion, the present study shows for the first time that the endogenous activation of postsynaptic CRF1 receptors in the CeLC is critically involved in pain-related synaptic changes and contributes to nociceptive and affective pain responses. Presynaptic CRF2 receptors have different cellular effects but may not play a major role in pain modulation by the amygdala.

\section{References}

Alheid GF, De Olmos JS, Beltramino CA (1995) Amygdala and extended amygdala. In: The rat nervous system (Paxinos G, ed), pp 495-578. San Diego: Academic.

Arzt E, Holsboer F (2006) CRF signaling: molecular specificity for drug targeting in the CNS. Trends Pharmacol Sci 27:531-538.

Asan E, Yilmazer-Hanke DM, Eliava M, Hantsch M, Lesch KP, Schmitt A (2005) The corticotropin-releasing factor (CRF)-system and monoaminergic afferents in the central amygdala: investigations in different mouse strains and comparison with the rat. Neuroscience 131:953-967.

Bale TL, Vale WW (2004) CRF and CRF receptors: role in stress responsivity and other behaviors. Annu Rev Pharmacol Toxicol 44:525-557.

Bird GC, Lash LL, Han JS, Zou X, Willis WD, Neugebauer V (2005) Protein kinase A-dependent enhanced NMDA receptor function in pain-related synaptic plasticity in rat amygdala neurones. J Physiol (Lond) 564:907-921.

Blank T, Nijholt I, Grammatopoulos DK, Randeva HS, Hillhouse EW, Spiess J (2003) Corticotropin-releasing factor receptors couple to multiple G-proteins to activate diverse intracellular signaling pathways in mouse hippocampus: role in neuronal excitability and associative learning. J Neurosci 23:700-707.

Borszcz GS, Leaton RN (2003) The effect of amygdala lesions on conditional and unconditional vocalizations in rats. Neurobiol Learn Mem 79:212-225.

Cabell L, Audesirk G (1993) Effects of selective inhibition of protein kinase $\mathrm{C}$, cyclic AMP-dependent protein kinase, and $\mathrm{Ca}^{2+}$-calmodulindependent protein kinase on neurite development in cultured rat hippocampal neurons. Int J Dev Neurosci 11:357-368.

Carrasquillo Y, Gereau RW (2007) Activation of the extracellular signalregulated kinase in the amygdala modulates pain perception. J Neurosci 27:1543-1551.

Chalmers DT, Lovenberg TW, Grigoriadis DE, Behan DP, De Souza EB (1996) Corticotrophin-releasing factor receptors: from molecular biology to drug design. Trends Pharmacol Sci 17:166-172.

Charney DS (2003) Neuroanatomical circuits modulating fear and anxiety behaviors. Acta Psychiatr Scand Suppl 38-50.

Chen BS, Roche KW (2007) Regulation of NMDA receptors by phosphorylation. Neuropharmacology 53:362-368.

Chen L, Huang LY (1992) Protein kinase C reduces $\mathrm{Mg}^{2+}$ block of NMDAreceptor channels as a mechanism of modulation. Nature 356:521-523.

Dautzenberg FM, Hauger RL (2002) The CRF peptide family and their receptors: yet more partners discovered. Trends Pharmacol Sci 23:71-77.

Deisz RA, Billard JM, Zieglgansberger W (1997) Presynaptic and postsynaptic $\mathrm{GABAB}$ receptors of neocortical neurons of the rat in vitro: differences in pharmacology and ionic mechanisms. Synapse 25:62-72.

Dumont EC, Martina M, Samson RD, Drolet G, Pare D (2002) Physiological properties of central amygdala neurons: species differences. Eur J Neurosci 15:545-552.

Erisir A, Lau D, Rudy B, Leonard CS (1999) Function of specific $\mathrm{K}^{+}$channels in sustained high-frequency firing of fast-spiking neocortical interneurons. J Neurophysiol 82:2476-2489.

Faber ES, Sah P (2003) $\mathrm{Ca}^{2+}$-activated $\mathrm{K}^{+}(\mathrm{BK})$ channel inactivation con- 
tributes to spike broadening during repetitive firing in the rat lateral amygdala. J Physiol (Lond) 552:483-497.

Gallagher RM, Verma S (2004) Mood and anxiety disorders in chronic pain. Prog Pain Res Management 27:139-178.

Gauriau C, Bernard J-F (2002) Pain pathways and parabrachial circuits in the rat. Exp Physiol 87:251-258.

Grachev ID, Fredickson BE, Apkarian AV (2001) Dissociating anxiety from pain: mapping the neuronal marker $\mathrm{N}$-acetyl aspartate to perception distinguishes closely interrelated characteristics of chronic pain. Mol Psychiatry $6: 256-258$.

Gray TS (1993) Amygdaloid CRF pathways. Role in autonomic, neuroendocrine, and behavioral responses to stress. Ann NY Acad Sci 697:53-60.

Greenwood-Van Meerveld B, Johnson AC, Cochrane S, Schulkin J, Myers DA (2005) Corticotropin-releasing factor 1 receptor-mediated mechanisms inhibit colonic hypersensitivity in rats. Neurogastroenterol Motil 17:415-422.

Greenwood-Van Meerveld B, Johnson AC, Schulkin J, Myers DA (2006) Long-term expression of corticotropin-releasing factor (CRF) in the paraventricular nucleus of the hypothalamus in response to an acute colonic inflammation. Brain Res 1071:91-96.

Gue M, Del Rio-Lacheze C, Eutamene H, Theodorou V, Fioramonti J, Bueno L (1997) Stress-induced visceral hypersensitivity to rectal distension in rats: role of CRF and mast cells. Neurogastroenterol Motil 9:271-279.

Han JS, Neugebauer V (2005) mGluR1 and mGluR5 antagonists in the amygdala inhibit different components of audible and ultrasonic vocalizations in a model of arthritic pain. Pain 113:211-222.

Han JS, Bird GC, Neugebauer V (2004) Enhanced group III mGluRmediated inhibition of pain-related synaptic plasticity in the amygdala. Neuropharmacology 46:918-926.

Han JS, Bird GC, Li W, Neugebauer V (2005a) Computerized analysis of audible and ultrasonic vocalizations of rats as a standardized measure of pain-related behavior. J Neurosci Methods 141:261-269.

Han JS, Li W, Neugebauer V (2005b) Critical role of calcitonin gene-related peptide 1 receptors in the amygdala in synaptic plasticity and pain behavior. J Neurosci 25:10717-10728.

Han JS, Fu Y, Bird GC, Neugebauer V (2006) Enhanced group II mGluRmediated inhibition of pain-related synaptic plasticity in the amygdala. Mol Pain 2:18-29.

Harrigan EA, Magnuson DJ, Thunstedt GM, Gray TS (1994) Corticotropin releasing factor neurons are innervated by calcitonin gene-related peptide terminals in the rat central amygdaloid nucleus. Brain Res Bull 33:529-534.

Heinricher MM, McGaraughty S (1999) Pain-modulating neurons and behavioral state. In: Handbook of behavioral state control (Lydic R, Baghdoyan HA, eds), pp 487-503. New York: CRC.

Hoare SR, Sullivan SK, Ling N, Crowe PD, Grigoriadis DE (2003) Mechanism of corticotropin-releasing factor type I receptor regulation by nonpeptide antagonists. Mol Pharmacol 63:751-765.

Hoare SR, Sullivan SK, Fan J, Khongsaly K, Grigoriadis DE (2005) Peptide ligand binding properties of the corticotropin-releasing factor (CRF) type 2 receptor: pharmacology of endogenously expressed receptors, G-protein-coupling sensitivity and determinants of CRF2 receptor selectivity. Peptides 26:457-470.

Ikeda R, Takahashi Y, Inoue K, Kato F (2007) NMDA receptor-independent synaptic plasticity in the central amygdala in the rat model of neuropathic pain. Pain 127:161-172.

Ji G, Neugebauer V (2007) Differential effects of CRF1 and CRF2 receptor antagonists on pain-related sensitization of neurons in the central nucleus of the amygdala. J Neurophysiol 97:3893-3904.

Ji G, Fu Y, Ruppert KA, Neugebauer V (2007) Pain-related anxiety-like behavior requires CRF1 receptors in the amygdala. Mol Pain 3:13-17.

Joanny P, Steinberg J, Oliver C, Grino M (1997) Glutamate and N-methyl$\mathrm{D}$-aspartate stimulate rat hypothalamic corticotropin-releasing factor secretion in vitro. J Neuroendocrinol 9:93-97.

Kasten MR, Rudy B, Anderson MP (2007) Differential regulation of action potential firing in adult murine thalamocortical neurons by Kv3.2, Kv1, and SK potassium and N-type calcium channels. J Physiol (Lond) 584:565-582.

Kunzel HE, Ising M, Zobel AW, Nickel T, Ackl N, Sonntag A, Holsboer F, Uhr M (2005) Treatment with a CRH-1-receptor antagonist (R121919) does not affect weight or plasma leptin concentration in patients with major depression. J Psychiatr Res 39:173-177.
Lariviere WR, Melzack R (2000) The role of corticotropin-releasing factor in pain and analgesia. Pain 84:1-12.

Li W, Neugebauer V (2004a) Block of NMDA and non-NMDA receptor activation results in reduced background and evoked activity of central amygdala neurons in a model of arthritic pain. Pain 110:112-122.

Li W, Neugebauer V (2004b) Differential roles of mGluR1 and mGluR5 in brief and prolonged nociceptive processing in central amygdala neurons. J Neurophysiol 91:13-24.

Li W, Neugebauer V (2006) Differential changes of group II and group III mGluR function in central amygdala neurons in a model of arthritic pain. J Neurophysiol 96:1803-1815.

Likhtik E, Pelletier JG, Paz R, Pare D (2005) Prefrontal control of the amygdala. J Neurosci 25:7429-7437.

Liu J, Yu B, Neugebauer V, Grigoriadis DE, Rivier J, Vale WW, ShinnickGallagher P, Gallagher JP (2004) Corticotropin-releasing factor and urocortin I modulate excitatory glutamatergic synaptic transmission. J Neurosci 24:4020-4029.

Lopez de Armentia M, Sah P (2004) Firing properties and connectivity of neurons in the rat lateral central nucleus of the amygdala. J Neurophysiol 92:1285-1294.

Lopez de Armentia M, Sah P (2007) Bidirectional synaptic plasticity at nociceptive afferents in the rat central amygdala. J Physiol (Lond) 581:961-970.

Martina M, Schultz JH, Ehmke H, Monyer H, Jonas P (1998) Functional and molecular differences between voltage-gated $\mathrm{K}^{+}$channels of fastspiking interneurons and pyramidal neurons of rat hippocampus. J Neurosci 18:8111-8125.

Martinez V, Wang L, Million M, Rivier J, Tache Y (2004) Urocortins and the regulation of gastrointestinal motor function and visceral pain. Peptides 25:1733-1744.

McDonald AJ, Mascagni F (2006) Differential expression of Kv3.1b and Kv3.2 potassium channel subunits in interneurons of the basolateral amygdala. Neuroscience 138:537-547.

McKay BE, Turner RW (2004) Kv3 $\mathrm{K}^{+}$channels enable burst output in rat cerebellar Purkinje cells. Eur J Neurosci 20:729-739.

McKernan MG, Shinnick-Gallagher P (1997) Fear conditioning induces a lasting potentiation of synaptic currents in vitro. Nature 390:607-611.

McNally GP, Akil H (2002) Role of corticotropin-releasing hormone in the amygdala and bed nucleus of the stria terminalis in the behavioral, pain modulatory, and endocrine consequences of opiate withdrawal. Neuroscience 112:605-617.

Million M, Grigoriadis DE, Sullivan S, Crowe PD, McRoberts JA, Zhou H, Saunders PR, Maillot C, Mayer EA, Tache Y (2003) A novel watersoluble selective CRF1 receptor antagonist, NBI 35965, blunts stressinduced visceral hyperalgesia and colonic motor function in rats. Brain Res 985:32-42.

Million M, Wang L, Wang Y, Adelson DW, Yuan PQ, Maillot C, Coutinho SV, McRoberts JA, Bayati A, Mattsson H, Wu V, Wei JY, Rivier J, Vale W, Mayer EA, Tache Y (2006) CRF2 receptor activation prevents colorectal distension induced visceral pain and spinal ERK1/2 phosphorylation in rats. Gut 55:172-181.

Misgeld U, Bijak M, Jarolimek W (1995) A physiological role for $\mathrm{GABA}_{\mathrm{B}}$ receptors and the effects of baclofen in the mammalian central nervous system. Prog Neurobiol 46:423-462.

Myers DA, Gibson M, Schulkin J, Greenwood Van-Meerveld B (2005) Corticosterone implants to the amygdala and type $1 \mathrm{CRH}$ receptor regulation: effects on behavior and colonic sensitivity. Behav Brain Res 161:39-44.

Neugebauer V (2006) Subcortical processing of nociceptive information: basal ganglia and amygdala. In: Pain (Cervero F, Jensen TS, eds), Handbook of clinical neurology, Vol 81, pp 141-158. Amsterdam: Elsevier.

Neugebauer V, Li W (2003) Differential sensitization of amygdala neurons to afferent inputs in a model of arthritic pain. J Neurophysiol 89:716-727.

Neugebauer V, Li W, Bird GC, Bhave G, Gereau RW (2003) Synaptic plasticity in the amygdala in a model of arthritic pain: differential roles of metabotropic glutamate receptors 1 and 5. J Neurosci 23:52-63.

Neugebauer V, Li W, Bird GC, Han JS (2004) The amygdala and persistent pain. The Neuroscientist 10:221-234.

Neugebauer V, Han JS, Adwanikar H, Fu Y, Ji G (2007) Techniques for assessing knee joint pain in arthritis. Mol Pain 3:8-20.

Nijsen M, Ongenae N, Meulemans A, Coulie B (2005) Divergent role for CRF1 and CRF2 receptors in the modulation of visceral pain. Neurogastroenterol Motil 17:423-432. 
Olpe HR, Karlsson G, Pozza MF, Brugger F, Steinmann M, Van RH, Fagg G, Hall RG, Froestl W, Bittiger H (1990) CGP 35348: a centrally active blocker of GABAB receptors. Eur J Pharmacol 187:27-38.

Pare D, Quirk GJ, Ledoux JE (2004) New vistas on amygdala networks in conditioned fear. J Neurophysiol 92:1-9.

Paxinos G, Watson C (1998) The rat brain in stereotaxic coordinates. New York: Academic.

Pedersen LH, Scheel-Kruger J, Blackburn-Munro G (2007) Amygdala GABA-A receptor involvement in mediating sensory-discriminative and affective-motivational pain responses in a rat model of peripheral nerve injury. Pain 127:17-26.

Pitler TA, Alger BE (1994) Differences between presynaptic and postsynaptic GABAB mechanisms in rat hippocampal pyramidal cells. J Neurophysiol 72:2317-2327.

Pollandt S, Liu J, Orozco-Cabal L, Grigoriadis DE, Vale WW, Gallagher JP, Shinnick-Gallagher P (2006) Cocaine withdrawal enhances long-term potentiation induced by corticotropin-releasing factor at central amygdala glutamatergic synapses via CRF, NMDA receptors and PKA. Eur J Neurosci 24:1733-1743.

Porter JT, Nieves D (2004) Presynaptic GABAB receptors modulate thalamic excitation of inhibitory and excitatory neurons in the mouse barrel cortex. J Neurophysiol 92:2762-2770.

Potes CS, Neto FL, Castro-Lopes JM (2006) Inhibition of pain behavior by GABA(B) receptors in the thalamic ventrobasal complex: effect on normal rats subjected to the formalin test of nociception. Brain Res 1115:37-47.

Quirk GJ, Gehlert DR (2003) Inhibition of the amygdala: key to pathological states? Ann NY Acad Sci 985:263-272.

Rainnie DG, Bergeron R, Sajdyk TJ, Patil M, Gehlert DR, Shekhar A (2004) Corticotrophin releasing factor-induced synaptic plasticity in the amygdala translates stress into emotional disorders. J Neurosci 24:3471-3479.

Reul JM, Holsboer F (2002) Corticotropin-releasing factor receptors 1 and 2 in anxiety and depression. Curr Opin Pharmacol 2:23-33.

Rhudy JL, Meagher MW (2001) The role of emotion in pain modulation. Curr Opin Psychiatry 14:241-245.

Rhudy JL, Meagher MW (2003) Negative affect: effects on an evaluative measure of human pain. Pain 104:617-626.

Rivier J, Gulyas J, Kirby D, Low W, Perrin MH, Kunitake K, DiGruccio M, Vaughan J, Reubi JC, Waser B, Koerber SC, Martinez V, Wang L, Tache Y, Vale W (2002) Potent and long-acting corticotropin releasing factor (CRF) receptor 2 selective peptide competitive antagonists. J Med Chem 45:4737-4747.

Rivier J, Gulyas J, Kunitake K, DiGruccio M, Cantle JP, Perrin MH, Donaldson C, Vaughan J, Million M, Gourcerol G, Adelson DW, Rivier C, Tache Y, Vale W (2007) Stressin1-A, a potent corticotropin releasing factor receptor 1 (CRF1)-selective peptide agonist. J Med Chem 50:1668-1674.

Rome HP, Rome JD (2000) Limbically augmented pain syndrome (LAPS): kindling, corticolimbic sensitization, and the convergence of affective and sensory symptoms in chronic pain disorders. Pain Med 1:7-23.

Rudy B, McBain CJ (2001) Kv3 channels: voltage-gated $\mathrm{K}^{+}$channels designed for high-frequency repetitive firing. Trends Neurosci 24:517-526.
Rudy B, Chow A, Lau D, Amarillo Y, Ozaita A, Saganich M, Moreno H, Nadal MS, Hernandez-Pineda R, Hernandez-Cruz A, Erisir A, Leonard C, VegaSaenz de ME (1999) Contributions of Kv3 channels to neuronal excitability. Ann NY Acad Sci 868:304-343.

Sacco T, De LA, Tempia F (2006) Properties and expression of Kv3 channels in cerebellar Purkinje cells. Mol Cell Neurosci 33:170-179.

Schiess MC, Callahan PM, Zheng H (1999) Characterization of the electrophysiological and morphological properties of rat central amygdala neurons in vitro. J Neurosci Res 58:663-673.

Schrader LA, Tasker JG (1997) Presynaptic modulation by metabotropic glutamate receptors of excitatory and inhibitory synaptic inputs to hypothalamic magnocellular neurons. J Neurophysiol 77:527-536.

Schwaber JS, Sternini C, Brecha NC, Rogers WT, Card JP (1988) Neurons containing calcitonin gene-related peptide in the parabrachial nucleus project to the central nucleus of the amygdala. J Comp Neurol 270:416-426.

Sinniger V, Porcher C, Mouchet P, Juhem A, Bonaz B (2004) c-fos and CRF receptor gene transcription in the brain of acetic acid-induced somatovisceral pain in rats. Pain 110:738-750.

Stiller CO, Taylor BK, Linderoth B, Gustafsson H, Warsame Afrah A, Brodin E (2003) Microdialysis in pain research. Adv Drug Deliv Rev 55:1065-1079.

Tache Y, Martinez V, Wang L, Million M (2004) CRF1 receptor signaling pathways are involved in stress-related alterations of colonic function and viscerosensitivity: implications for irritable bowel syndrome. Br J Pharmacol 141:1321-1330.

Takahashi LK (2001) Role of CRF(1) and CRF(2) receptors in fear and anxiety. Neurosci Biobehav Rev 25:627-636.

Tanimoto S, Nakagawa T, Yamauchi Y, Minami M, Satoh M (2003) Differential contributions of the basolateral and central nuclei of the amygdala in the negative affective component of chemical somatic and visceral pains in rats. Eur J Neurosci 18:2343-2350.

Turk DC (2003) Cognitive-behavioral approach to the treatment of chronic pain patients. Reg Anesth Pain Med 28:573-579.

Ulrich-Lai YM, Xie W, Meij JTA, Dolgas CM, Yu L, Herman JP (2006) Limbic and HPA axis function in an animal model of chronic neuropathic pain. Physiol Behav 88:67-76.

Vit JP, Clauw DJ, Moallem T, Boudah A, Ohara PT, Jasmin L (2006) Analgesia and hyperalgesia from CRF receptor modulation in the central nervous system of Fischer and Lewis rats. Pain 121:241-260.

Woodruff AR, Sah P (2007) Networks of parvalbumin-positive interneurons in the basolateral amygdala. J Neurosci 27:553-563.

Wu LG, Saggau P (1997) Presynaptic inhibition of elicited neurotransmitter release. Trends Neurosci 20:204-212.

Wyllie DJ, Manabe T, Nicoll RA (1994) A rise in postsynaptic $\mathrm{Ca}^{2+}$ potentiates miniature excitatory postsynaptic currents and AMPA responses in hippocampal neurons. Neuron 12:127-138.

Zobel AW, Nickel T, Kunzel HE, Ackl N, Sonntag A, Ising M, Holsboer F (2000) Effects of the high-affinity corticotropin-releasing hormone receptor 1 antagonist R121919 in major depression: the first 20 patients treated. J Psychiatr Res 34:171-181. 